\title{
Current radiological strategies for the assessment of right lower quadrant abdominal pain
}

\begin{abstract}
Authors:
Pumersha Naidoo ${ }^{1}$

Bhugwan Singh ${ }^{2}$

Affiliations:

${ }^{1}$ Department of Radiology, Nelson R. Mandela School of Medicine, University of KwaZulu-Natal, South Africa

${ }^{2}$ Department of Surgery, Nelson R. Mandela School of Medicine, University of KwaZulu-Natal, South Africa

Correspondence to:

Pumersha Naidoo

Email:

pumershanaidoo@gmail.com

Postal address:

25 The Curl, Sunningdale,

Durban 4051, South Africa

Dates:

Received: 18 July 2014

Accepted: 14 Sept. 2014

Published: 05 Dec. 2014

How to cite this article: Naidoo P, Singh B. Current radiological strategies for the assessment of right lower quadrant abdominal pain. S Afr J Rad. 2014;18(1) Art. \#695, 15 pages. http:// dx.doi/org.10.4102/sajr. v18i1.695

\section{Copyright:}

(C) 2014. The Authors. Licensee: AOSIS

OpenJournals. This work is licensed under the Creative Commons Attribution License.
\end{abstract}

Read online:
Right lower quadrant abdominal pain is a common clinical entity. Imaging and the radiologist play an integral role in achieving a diagnosis, so guiding prompt management of patients. This review discusses the spectrum of pathology and imaging findings, and highlights and contrasts the preferred imaging modalities in different subsets of patients.

\section{Introduction}

Right lower quadrant abdominal pain is a common clinical occurrence, with a wide spectrum of aetiologies that can present a diagnostic challenge for clinicians. Appendicitis is invariably the first differential diagnosis and most common cause of right lower quadrant pain. However, other considerations include infective, inflammatory and malignant conditions involving the ileo-caecal region, right colon, mesentery and surrounding anatomical structures. ${ }^{1}$ HIV has affected the spectrum of pathology afflicting the right lower quadrant and altered the traditional diagnostic challenges presented by this anatomical region. The attendant clinician must be alert to this influence.

Imaging is currently at the forefront in assessing and diagnosing patients with right lower quadrant pain, thus guiding appropriate clinical management. Ultrasound (US) is the preferred imaging modality in children, pregnant women, and generally young patients, owing to the absence of ionising radiation. Advances in computed tomography (CT) with multiplanar reformations and 3D reconstruction have led to some clinicians considering multi-detector CT (MDCT) as the modality of choice when evaluating patients with right lower quadrant pain. CT is considered to be the first line imaging investigation for diffuse or peritonitic clinical pictures, and in elderly patients. ${ }^{1,2}$

Magnetic resonance imaging (MRI) has an emerging imaging role in female patients being assessed for gynaecological diseases - during pregnancy for non-obstetric conditions - and in patients where iodinated contrast is contraindicated, as well as for the evaluation of Crohn's disease. ${ }^{1,3,4}$ MRI offers short imaging protocols of approximately 10 minutes, and high contrast resolution, without the use of intravenous contrast or radiation burden. MRI and CT yield high sensitivities and specificities, without being user dependent. ${ }^{5}$

In this review, we consider the spectrum and typical imaging findings of common pathologies affecting the right lower quadrant. We highlight the preferred imaging modalities in accordance with the ALARA (as low as reasonably achievable) principle and diagnostic yield. ${ }^{1}$

\section{Inflammatory and infective conditions Acute appendicitis}

Acute appendicitis is the most common non-traumatic abdominal emergency. However, only one-half of patients have a classical presentation (leucocytosis, fever and right lower quadrant pain), and the exact cause may be multifactorial. Currently, plain film radiography has a limited role, and has been superseded by US and CT. ${ }^{4} \mathrm{MRI}$ is beneficial in those patients for whom a CT scan is not warranted and for whom ultrasound is inconclusive. ${ }^{5}$ Using high-frequency US with mild compression, an inflamed appendix is typically dilated - more than $6 \mathrm{~mm}$ in diameter. An appendicular wall thickness of more than $3 \mathrm{~mm}$ may be present with peri-appendicular or pericaecal hyperechogenicity - in keeping with fat infiltration from the inflammatory process (Figure 1). ${ }^{2}$

Typical CT features of an inflamed appendix, using multi-planar reconstruction (MPR), manifest as enlargement of the appendix (diameter $>7 \mathrm{~mm}$ ), mural thickening and enhancement, and periappendiceal fat stranding (Figure 2). 


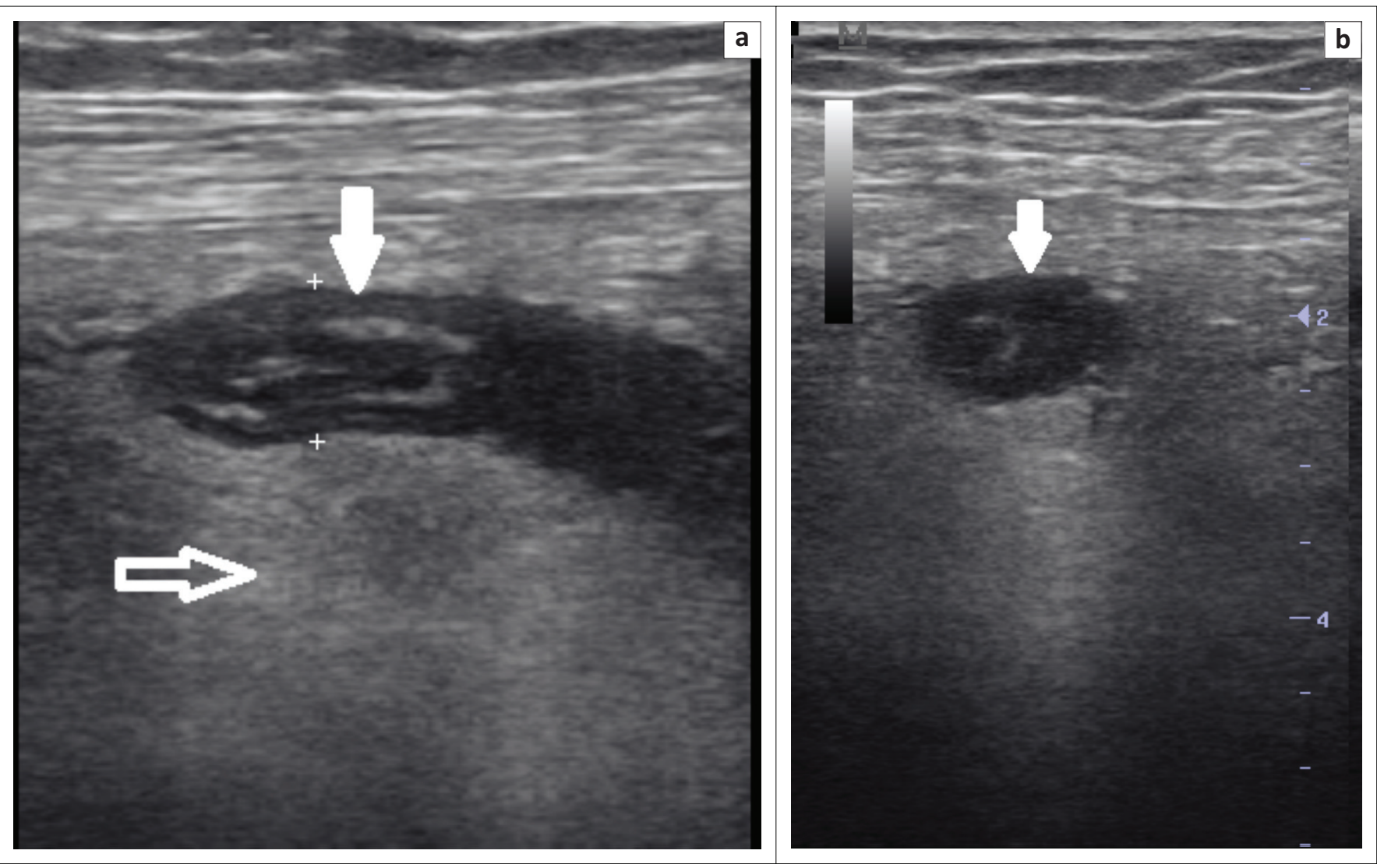

FIGURE 1: Acute uncomplicated appendicitis in a 24-year-old man. Longitudinal (a) and transverse (b) ultrasound images demonstrate a thickened inflamed appendix that has increased in diameter (solid arrow). There is peri-appendiceal hyperechogenicity in keeping with surrounding inflammation (open arrow).
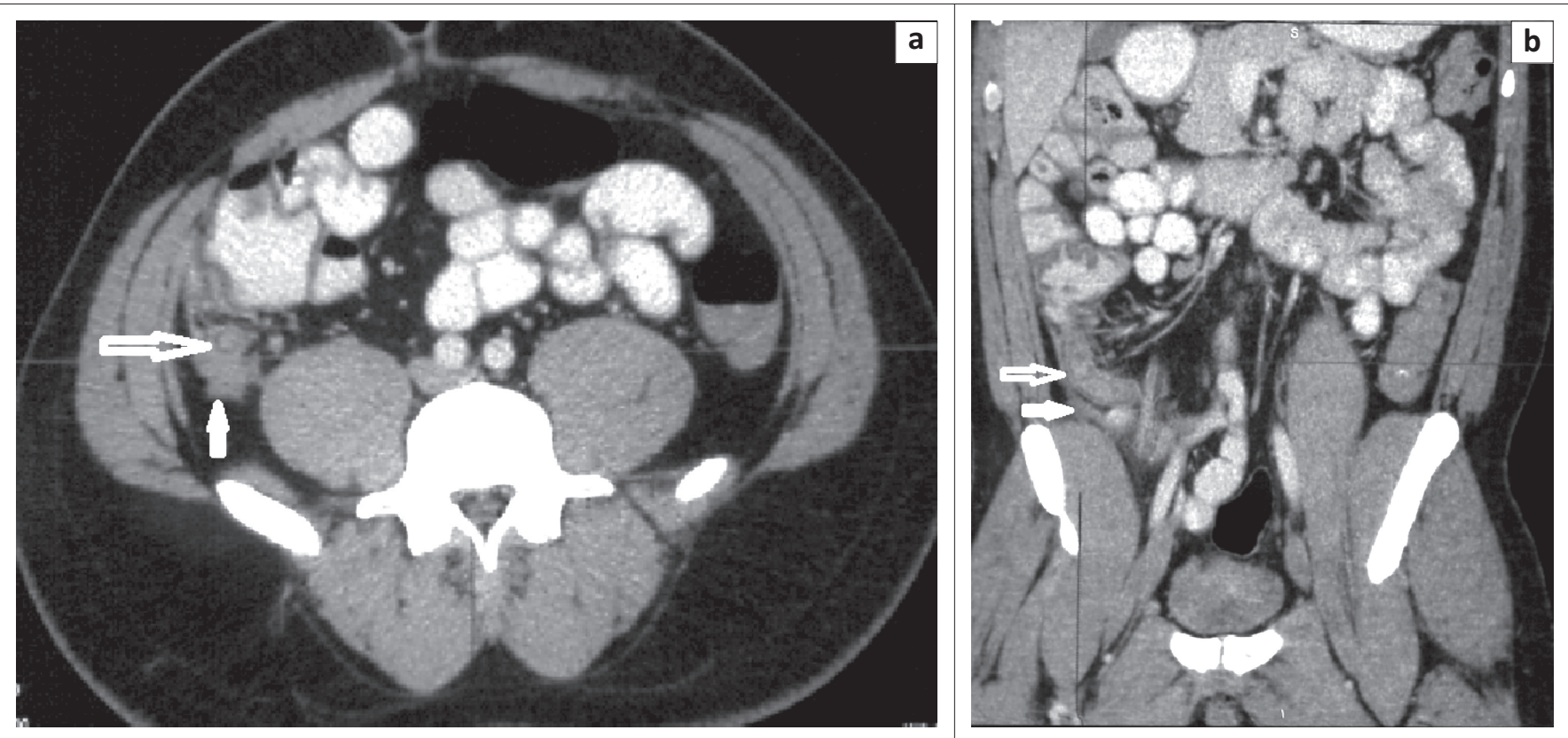

FIGURE 2: Axial (a) and coronal (b) CT images of a young adult showing acute appendicitis with appendicular wall enhancement and thickening (open arrow) with surrounding fat stranding and fluid (solid arrow).

Secondary signs include the presence of an appendicolith, focal wall thickening of the terminal ileum or caecum, and lack of gas and oral contrast within the appendix. Focal caecal wall thickening results in funnelling of oral contrast, termed the arrowhead sign. The complications associated with acute appendicitis include perforation, a peri-appendiceal abscess, pericaecal phlegmon, an extraluminal appendicolith, and small bowel obstruction (Figure 3). ${ }^{6,7,8}$

Distal appendicitis is diagnosed when a normal proximal appendix is visualised with an inflamed distal portion. A transition point is visualised with distal luminal narrowing 

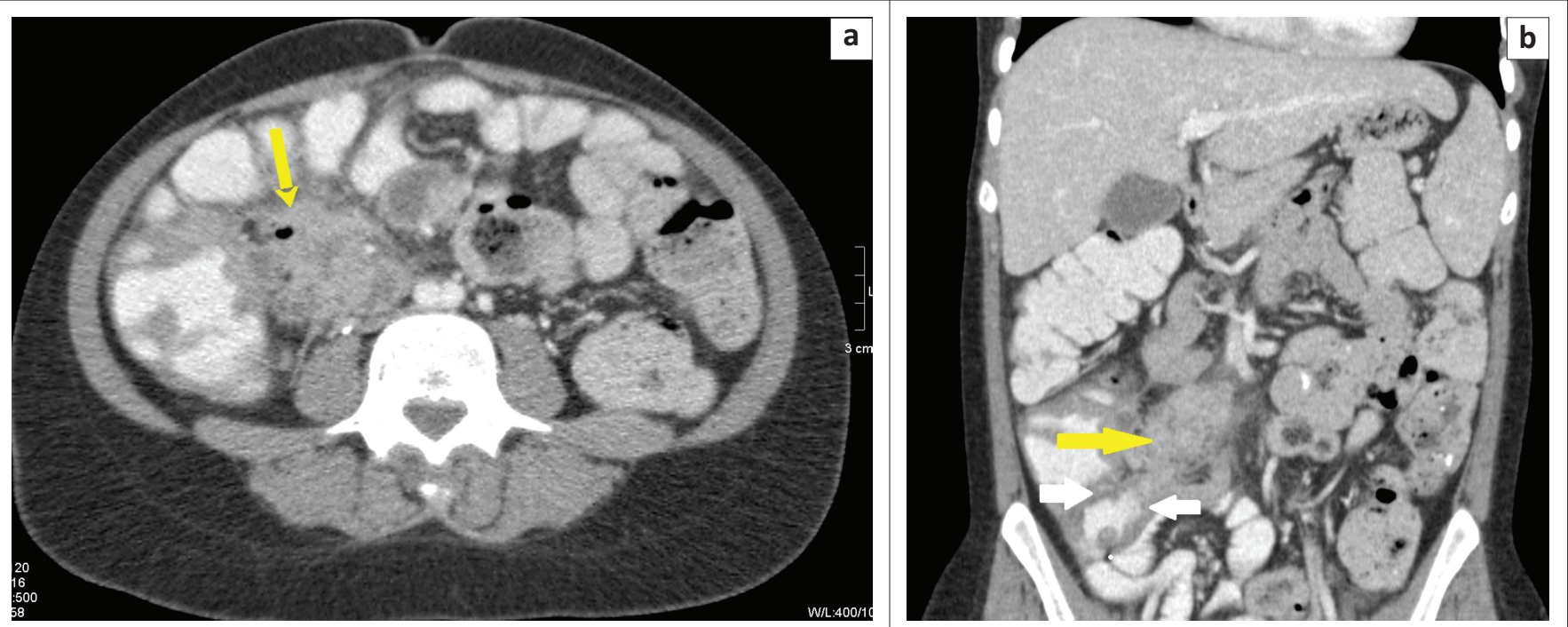

$\mathrm{CT}$, computed tomography.

FIGURE 3: Axial (a) and coronal (b) CT scan images of a 26-year-old woman demonstrate complicated appendicitis with caecal wall thickening (white solid arrows), periappendiceal phlegmon and extraluminal air (yellow arrows).
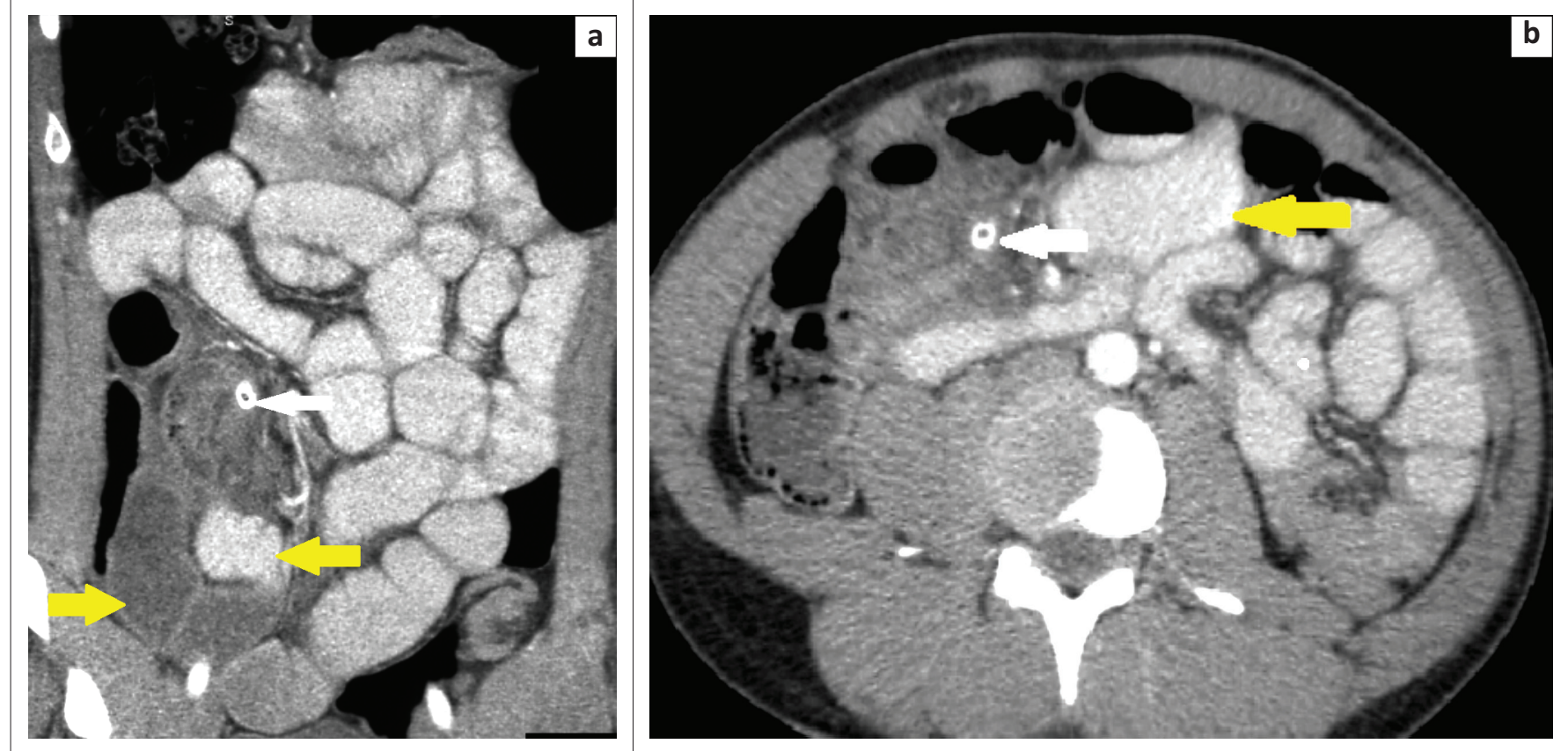

$\mathrm{CT}$, computed tomography

FIGURE 4: CT images of a 30-year-old man with acute appendicitis. Coronal (a) and axial (b) images demonstrate an appendicolith (white arrows) within an inflamed, enlarged appendix complicated by an appendicular mass and small bowel obstruction (yellow arrows).

and wall thickening or enlargement. Surrounding inflammatory changes are usually present; however, there is no caecal apical thickening or the arrowhead sign, as these are contiguous inflammatory changes. The normal appearance of the proximal appendix can lead to a missed diagnosis of distal appendicitis; therefore it is important to trace the appendix in its entirety. ${ }^{5,9}$

Stump appendicitis is a rare complication of appendicectomy that can occur from 2 months to 50 years post-surgery. It occurs when the appendiceal remnant becomes inflamed. The imaging features are similar to acute appendicitis. The increased incidence of stump appendicitis is thought to be directly related to the length of the stump (longer stumps are more prone to infection) and the growing number of laparoscopic appendicectomies. It is important to remember that a past history of appendicectomy does not exclude appendicitis. ${ }^{10,11}$

An appendicular mass or lump may be individualised; there can be adhesion of adjacent viscera (ileum, bladder, greater omentum) to the infectious location (Figure 4). ${ }^{2}$

Factors that complicate the diagnosis of appendicitis when using CT include lack of intra-abdominal fat or an unusual location of the caecum or appendix. Intra-abdominal fat acts as a natural contrast agent, allowing easy visualisation of an 
inflamed appendix. Therefore, in thin patients, the appendix may be difficult to visualise, leading to a false negative diagnosis of appendicitis. Since the caecum is a highly mobile structure and variable in position, locating the ileocaecal valve and accordingly then the appendix, may be beneficial. Multiplanar reconstruction (MPR) images are useful in visualising a retrocaecal, pelvic or transmesocolic appendix. ${ }^{6}$ Two recent studies assessed the value of a non-visualised appendix in patients with clinically suspected appendicitis. They reported that the absence of a visualised appendix on CT almost excludes acute appendicitis (negative predictive value $98 \%) .{ }^{12,13}$

Acute appendicitis is the most common gastrointestinal emergency requiring surgery in pregnant patients. The clinical manifestations in pregnancy are nonspecific and the caecum is displaced anteriorly and out of the pelvis, which makes visualisation of the appendix difficult. There is superior migration and rotation of the appendix as the pregnancy progresses, with the appendix frequently being found in the right upper quadrant.

There is a longstanding dilemma when considering the use of diagnostic imaging for evaluating pregnant patients with non-obstetric conditions such as acute appendicitis. Imaging modalities that do not make use of ionising radiation (such as US and MRI) are preferred as first options. If ionising radiation is to be used, a low radiation dose $\mathrm{CT}$ scan must be performed. ${ }^{3}$ The American College of Radiology (ACR) criteria for evaluating pregnant patients for this clinical challenge include the use of targeted right lower quadrant US with graded compression as the first-line imaging modality, with MRI as second option, and followed by abdominal CT scan., ${ }^{3,14}$

With targeted compression US, the appendix is better visualised in the first two trimesters. In the third trimester, detection can be improved by placing the patient in the left lateral decubitus position; however, this reduces sensitivity. The sonographic features are similar to a non-gravid patient.

If US evaluation is indeterminate and further imaging is clinically indicated, MRI may be undertaken. ${ }^{3}$ MRI allows cross-sectional imaging with identification of appendicitis, and with no exposure to ionising radiation. With excellent softtissue contrast resolution, additional structures may be viewed, thereby excluding other sources of abdominal pain. On MRI, the imaging features of appendicitis include an appendiceal diameter $>7 \mathrm{~mm}$, wall thickness $>2 \mathrm{~mm}$, T2 high signal intensity in the wall and T2 hyperintensity in the peri-appendiceal fat stranding and surrounding fluid. ${ }^{4}$ In the non-pregnant patient, contrast-enhanced and diffusion-weighted imaging may be of value - especially in patients who have equivocal wall thickness and no peri-appendiceal fat stranding. Strong contrast enhancement or restricted diffusion is indicative of appendicitis. In general, the major drawbacks of MRI are high cost, long imaging times and limited availability.,

Appendicitis in pregnant patients is associated with premature labour, foetal mortality and a higher rate of perforation than in the general population. There should be no delay in the diagnosis. If MRI cannot be performed, $\mathrm{CT}$ of the abdomen and pelvis should be used as a secondline imaging modality. However, clinicians and radiologists must be aware of the theoretical risk of radiation-induced childhood cancer (approximately one cancer per 500 foetuses exposed to $30 \mathrm{mGy}$ ). Intravenous and oral contrast agents are preferred in some centres to improve visualisation of the appendix in pregnant patients. ${ }^{3,15}$

\section{Crohn's disease}

Crohn's disease is a chronic relapsing auto-immune disorder. Whilst predominantly affecting young patients (between 15 and 30 years), it may occur in older patients up to 65 years of age. The disorder can manifest anywhere in the gastrointestinal tract. The ileocaecal region is the most affected and often mimics acute appendicitis. A CT scan excellently depicts the extent and severity of Crohn's disease. Typical CT scan findings include bowel wall thickening (generally $>1 \mathrm{~cm}$ ), mucosal hyperenhancement, pericolonic fat stranding, and mural stratification owing to intramural oedema. Segmental involvement of the bowel with skipped normal areas are helpful in distinguishing Crohn's disease from ulcerative colitis. Further findings, such as engorgement of the vasa recta that penetrate the bowel wall (the comb sign), are an important feature of active disease (Figure 5).

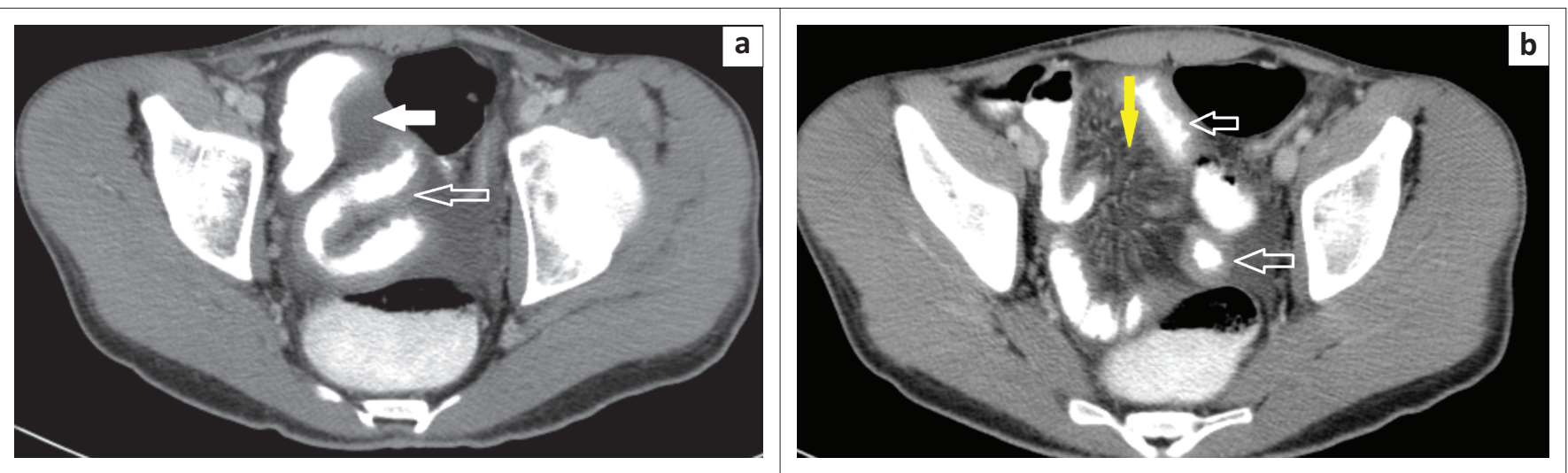

FIGURE 5: CT images of a patient with Crohn's disease. Axial images ( $a, b)$ show a markedly thickened wall of the terminal ileum (open arrows) with interloop fluid (solid white arrow) and comb sign (yellow arrow). 

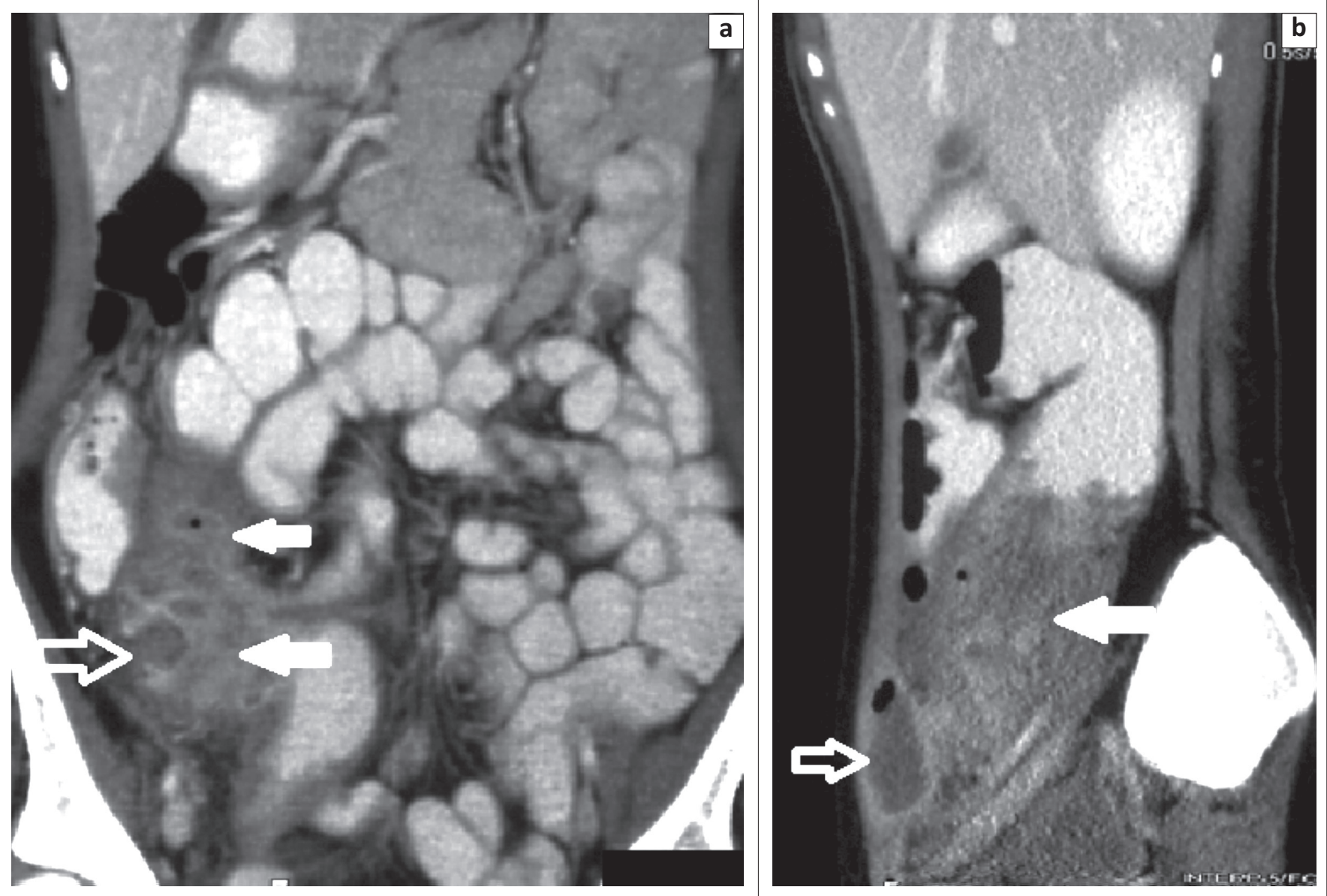

$\mathrm{CT}$, computed tomography.

FIGURE 6: CT images of a known Crohn's disease patient. Coronal (a) and sagittal (b) images demonstrate bowel wall thickening of the caecum and terminal ileum with mucosal hyperenhancement (solid arrows) complicated by an abscess extending into the anterior abdominal wall (open arrow).

Sclerolipomatous or fibrofatty proliferation along the mesenteric border of the affected bowel (the creeping fat sign) may be visualised. Mesenteric lymph nodes may also be present. Associated complications include fistulae, abscesses and small bowel strictures. With the aid of CT MPR, these complications are easily characterised (Figure 6).

Positive oral contrast agents may allow better depiction of fistulous tracts; however, this may obscure bowel wall hyperenhancement. MRI and MR enterography demonstrate similar bowel-related imaging findings noted on CT scan.

Owing to the young patient population affected by Crohn's disease and its chronicity, MRI is considered as the firstline imaging option in some centres, to reduce the radiation burden. ${ }^{1,2,16}$ CT enterography and small bowel followthrough studies also have high appropriateness ratings in the diagnosis and monitoring of Crohn's disease. ${ }^{17}$ MRI short tau inversion recovery (STIR) and T2-weighted sequences allow correct localisation of the inflammatory process and the extent of disease. Contrast-enhanced sequences can estimate the severity of the episode and also depict complications such as perforation and abscesses (Figure 7).

The use of diffusion-weighted imaging (DWI) appears to be promising, with restricted diffusion believed to be strongly correlated with severity and complications. ${ }^{5}$ A recent study assessed the capability of MRI to quantitatively assess the response to therapy in Crohn's disease. ${ }^{18}$ The results clearly showed the distinction between normal and pathological bowel wall, and depicted significant variation in bowel wall thickness and enhancement, so reflecting any favourable response to treatment.

\section{Diverticulitis}

Diverticulitis is a common cause of abdominal pain. When encountered in the right lower quadrant, it may be caused by diverticulitis in a loop of the sigmoid colon located in the right iliac fossa or, less commonly, the caecum or ascending colon. Typical features on CT include extensive pericolonic fat stranding (maximal at the site of the diverticulae), mesenteric fluid and bowel wall thickening with enhancement. It is important to differentiate diverticulitis from acute appendicitis; the key finding is visualisation of a normal appendix. Right-sided diverticulae are less common and frequently associated with a stercolith. Furthermore, ileal diverticulae are less frequent than colonic diverticulae; ileal diverticulae are located on the mesenteric border and are usually asymptomatic. When ileal diverticulae are inflamed, these must also be distinguished from appendicitis. 

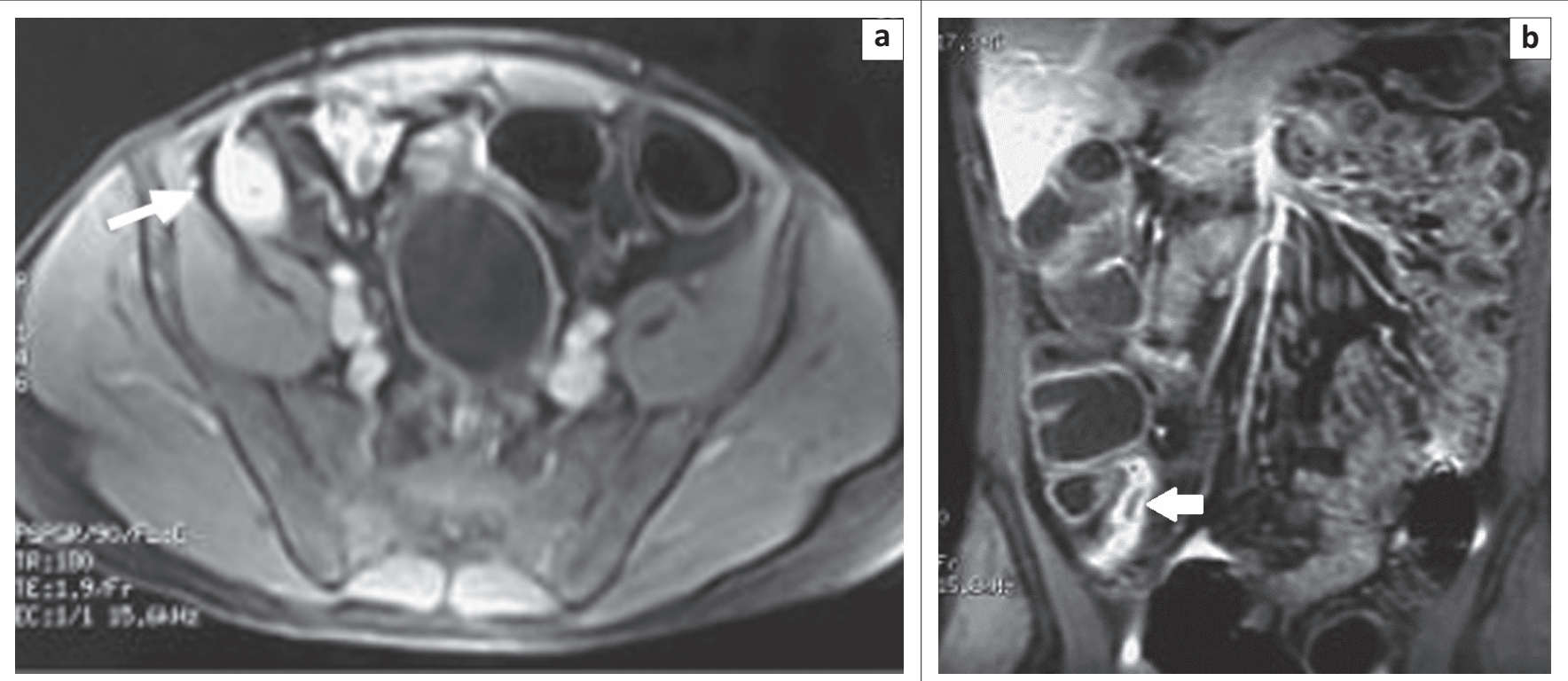

Source: Sempere et al. ${ }^{18}$

FIGURE 7: Thirty-three-year-old patient with known Crohn's disease. Axial (a) and coronal (b) post-contrast fat suppression T1-weighted MRI demonstrates marked wall thickening of the terminal ileum with hyperenhancement (white arrows).

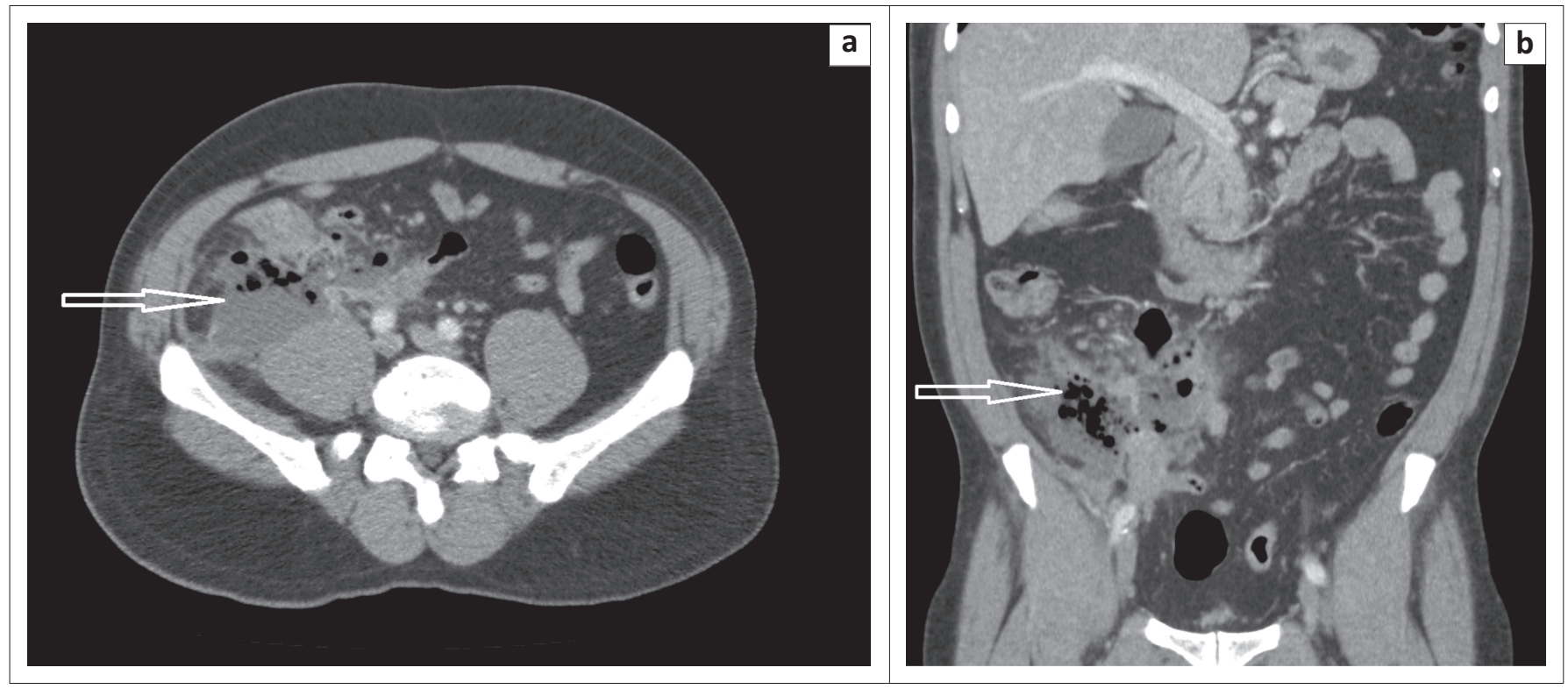

FIGURE 8: Complicated diverticulitis. Axial (a) and coronal (b) CT images show a rim-enhancing hypodense abscess (open arrows) in a patient with caecal diverticulae.

Complications of diverticulitis include fistulae, abscesses, free perforation and bowel obstruction (Figure 8). ${ }^{1,2,16}$

$\mathrm{CT}$ is an effective imaging modality that enables prompt diagnosis. Using coronal STIR MRI sequences, the area of inflammation can also be readily identified. Guided by this, bowel wall thickening, diverticulae and a narrowed lumen can be visualised. The inflamed areas will enhance on the post-contrast images and complications can be readily detected.

\section{Tuberculous enterocolitis}

Tuberculosis (TB) is endemic in the South African population, with a marked increase resulting from the AIDS epidemic. TB involvement of the gastrointestinal tract is well recognised, with the ileocaecal region most commonly affected (Figure 9).

With barium studies, an early manifestation is spasm and hypermobility, with oedema of the ileocaecal valve leading to its incompetence (Figure 10).

The caecum and terminal ileum are usually both affected; the CT features are concentric mural thickening and enhancement, which may cause luminal narrowing leading to proximal bowel dilatation and obstruction (Figure 11).

Advanced gastrointestinal TB characteristically appears as napkin ring stenosis, with a conically shaped, shrunken caecum retracted out of the right iliac fossa. ${ }^{19}$ 
It can be a radiological and clinical challenge to differentiate TB from Crohn's disease, considering the overlap in clinical presentation and imaging features (Table 1). This is important as it has significant therapeutic implications. ${ }^{20}$

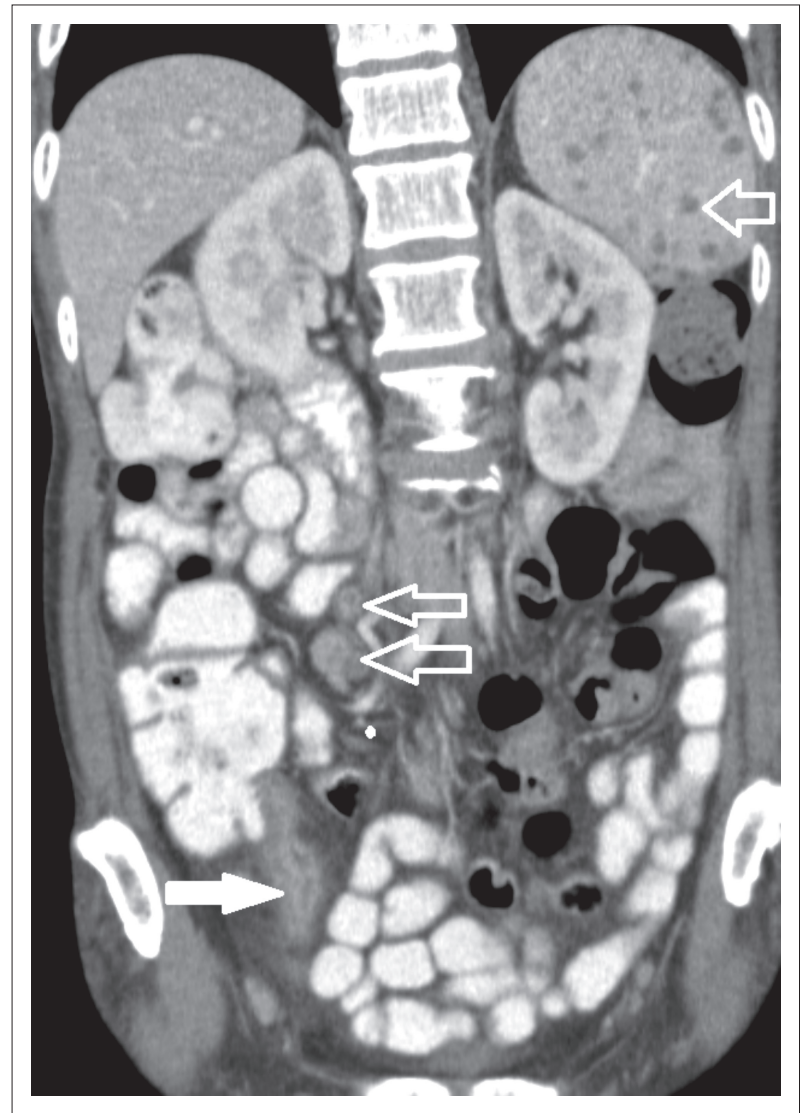

$\mathrm{CT}$, computed tomography.

FIGURE 9: An interesting case of a patient with proven appendicular tuberculosis. Coronal CT image shows mucosal hyperenhancement and wall thickening of the appendix (solid arrow), with low-density ileocaecal lymphadenopathy (long open arrows) and numerous splenic granulomas (short open arrow).

\section{Epiploic appendagitis}

First described by Lynn et al. in the mid-1950s, epiploic appendagitis is a well-recognised cause of pain in the right lower quadrant. ${ }^{2,21}$ It is thought to be caused by inflammatory and ischaemic changes secondary to torsion or venous thrombosis of the epiploic appendages. The diagnosis is usually established with $\mathrm{CT}$, allowing early recognition and conservative management. The CT appearance is that of an oval lesion of fat density with a hyperattenuating rim. Pericolonic fat attenuation and wall thickening of the adjacent colon may also be present (Figure 12). ${ }^{1,17,21}$

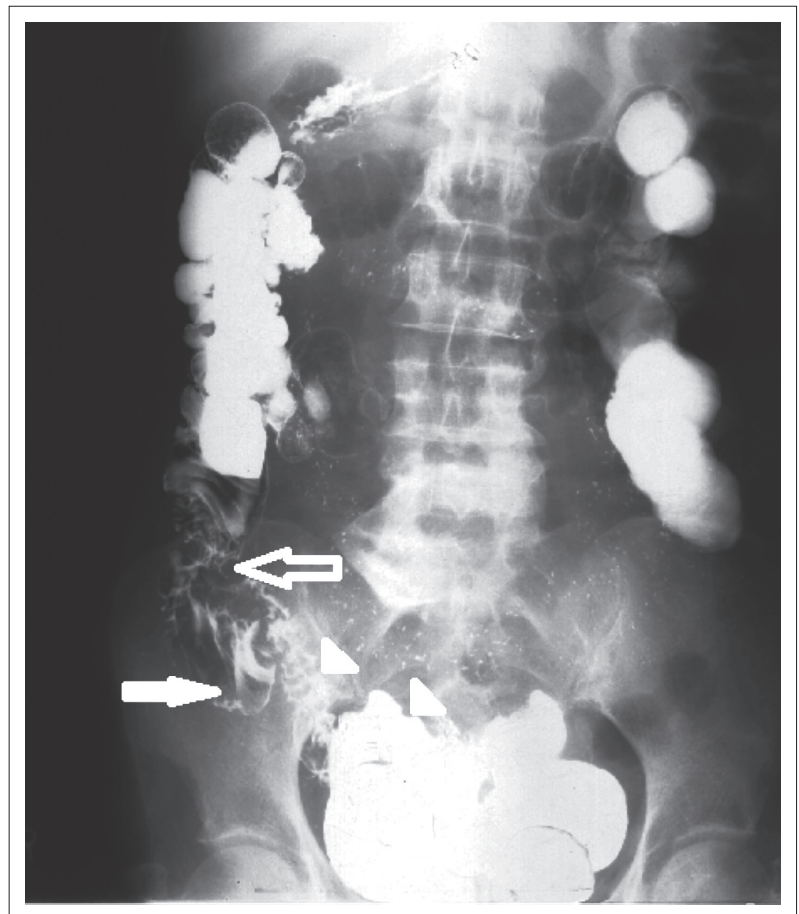

FIGURE 10: Spot film (AP supine) in a barium enema series of a patient with tuberculosis demonstrating a marked thickened caecum (solid arrow), ileocaceal valve (open arrow) and terminal ileum (arrowheads). There is reflux of contrast into the ileum consistent with an incompetent ileocaecal valve.
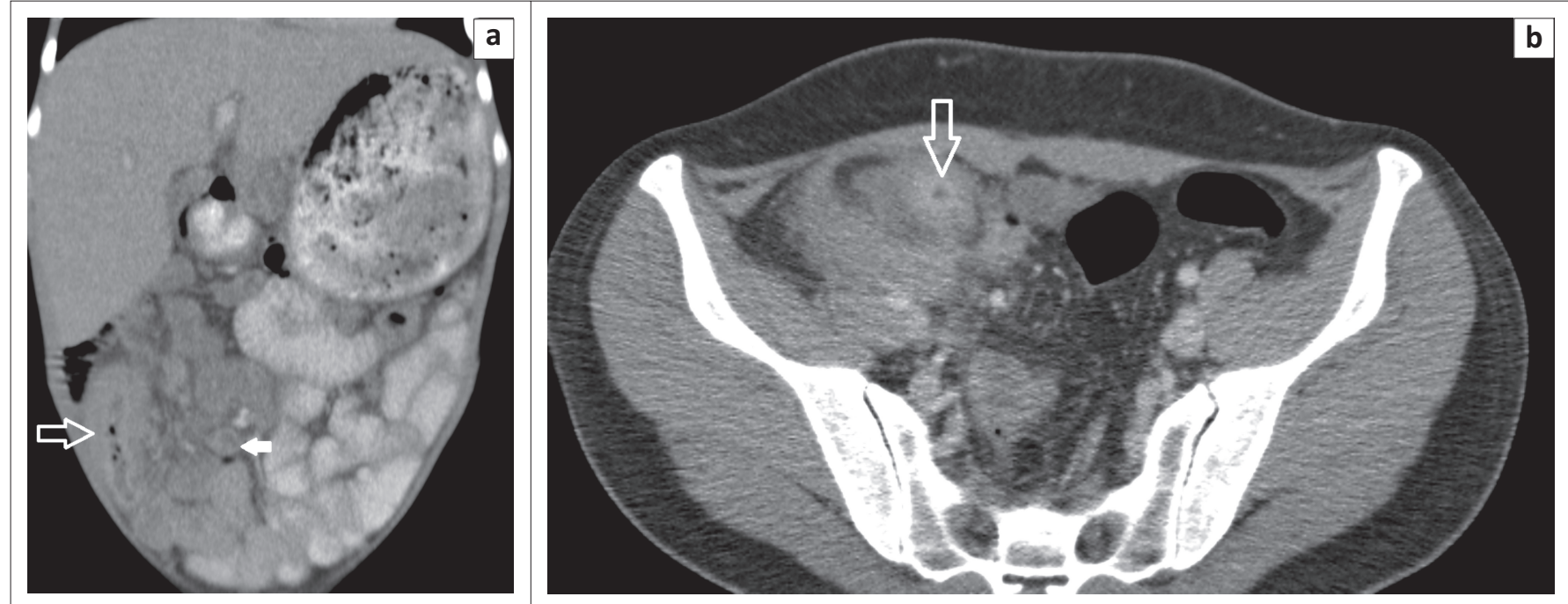

FIGURE 11: CT images of a 29-year-old woman with abdominal tuberculosis. Coronal image (a) reveals significant ileal wall thickening causing luminal attenuation (open arrow). There are several ileo-caecal lymph nodes of low-density (small solid arrow). Axial image (b) demonstrates the 'target' or 'halo' appearance of tuberculosis (open arrow). 
TABLE 1: Contrast fluoroscopy and CT findings in TB and Crohn's disease.

\begin{tabular}{|c|c|c|}
\hline Features & Tuberculosis & Crohn's disease \\
\hline Distribution & Ileocaecal region most common site in intestinal TB & Ileum involved, sparing of the ileocaecal valve \\
\hline \multirow[t]{3}{*}{ Contrast fluoroscopy } & Strictures are short, concentric and smooth & $\begin{array}{l}\text { Long, eccentric strictures with sacculations along the anti-mesenteric } \\
\text { border }\end{array}$ \\
\hline & Ulcers less common - round or oval in outline & Apthous ulcers pathognomonic \\
\hline & Enteroliths encountered & Perforation and fistulae more common \\
\hline \multirow[t]{5}{*}{ CT } & Fibrofatty proliferation uncommon & Fibrofatty proliferation of the mesentery \\
\hline & Mural thickening without stratification & Mural thickening with stratification in active disease \\
\hline & Hypodense lymph nodes with caseation and rim enhancement & Mild lymphadenopathy \\
\hline & Mesenteric inflammation but no vascular engorgement & Mesenteric hypervascularity (comb sign) \\
\hline & High-density ascites & Abscesses \\
\hline
\end{tabular}

Source: Pulimood et al. ${ }^{20}$

CT, computed tomography; TB; tuberculosis.
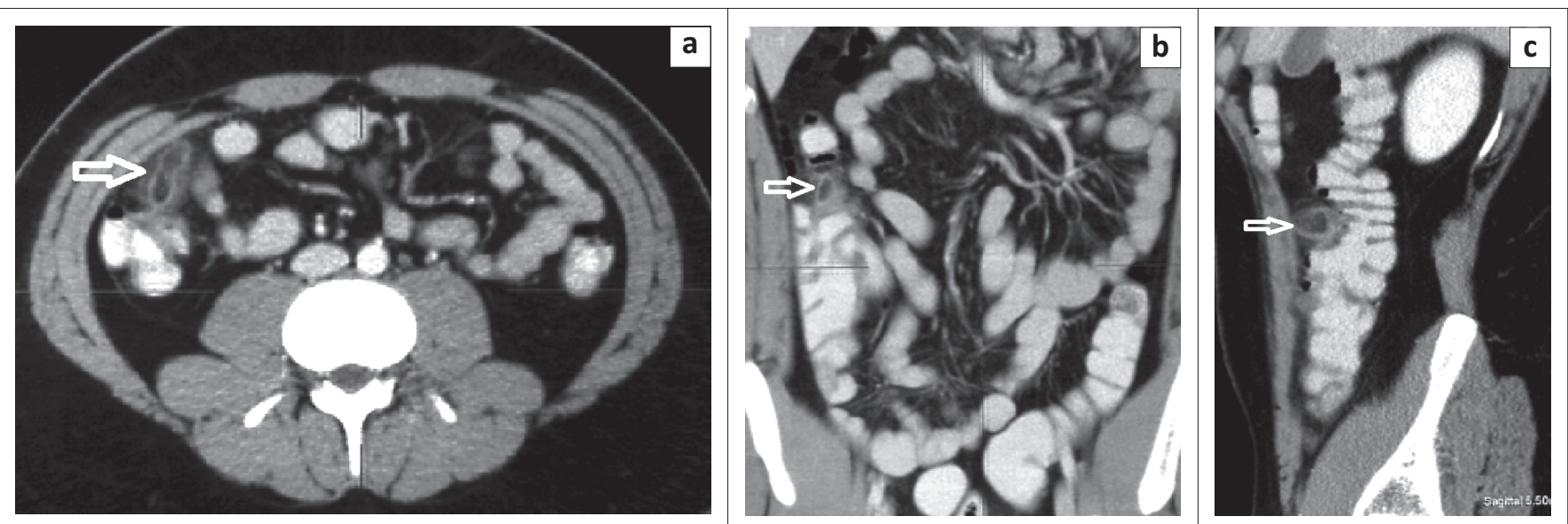

$\mathrm{CT}$, computed tomography.

FIGURE 12: Example of classic epiploic appendagitis. Axial (a), coronal (b) and sagittal (c) CT images show an inflamed epiploic appendage (open arrow) with the typical appearance of a pericolic oval lesion of fat attenuation with an enhancing rim and surrounding fat stranding.

\section{Right lower quadrant pain associated with immunosuppression Neutropaenic colitis (typhilitis)}

Neutropaenic colitis usually occurs in patients receiving chemotherapy for malignancies such as leukaemia, and for other immunosuppressive states. Clinically, it manifests with right lower quadrant pain, fever, diarrhoea and sometimes peritonitis. CT is considered the study of choice, and the features include caecal dilatation, circumferential wall thickening, intramural air and pericaecal fat stranding and fluid (Figure 13).

The presence of pneumoperitoneum, pneumatosis, gastrointestinal bleeding and fluid collections may require urgent surgical care. In an immunocompromised patient with symmetrical and circumferential caecal wall thickening, neutropaenic colitis should be suggested first. ${ }^{1,2,16}$

\section{Right lower quadrant pain associated with neoplastic conditions \\ Lymphoma}

Ileocaecal lymphoma is not uncommon. The four forms of ileocaecal lymphoma are the circumferential, polypoid, ulcerative and aneurysmal varieties. Ileocaecal lymphoma usually manifests as areas of bowel wall thickening with uniform attenuation and poor enhancement. Long segments of bowel involvement may be demonstrated. Signs of bowel obstruction are uncommon. The polypoidal variety can act as lead point for intussusception. The ulcerative form can develop fistulous tracts with adjacent structures. The aneurysmal form may demonstrate dilatation of the lumen of the bowel or cavity of the lymphoid mass. Enlarged mesenteric and retroperitoneal lymph nodes are common (Figure 14). ${ }^{1}$

\section{Colonic carcinoma}

Most colorectal carcinomas are adenocarcinomas. In comparison with the left colon, and owing to the larger calibre of the right colon, tumours in the latter location can grow to a large size without causing bowel obstruction (Figure 15).

Patients may present with rectal bleeding, anaemia or a palpable mass. ${ }^{1,16} \mathrm{CT}$ scanning (MDCT and CT colonography) can be used for screening of colon carcinoma for the staging of the disease, for assessing and staging of recurrent disease, and also for detection of distant metastases. ${ }^{22}$ Carcinomas may demonstrate variable appearances, and perforation can occur, leading to peritonitis or intraperitoneal abscess formation (Figure 16).

Abscess formation and peritonitis may simulate an inflammatory process rather than a malignancy (Figure 17). ${ }^{1}$ 

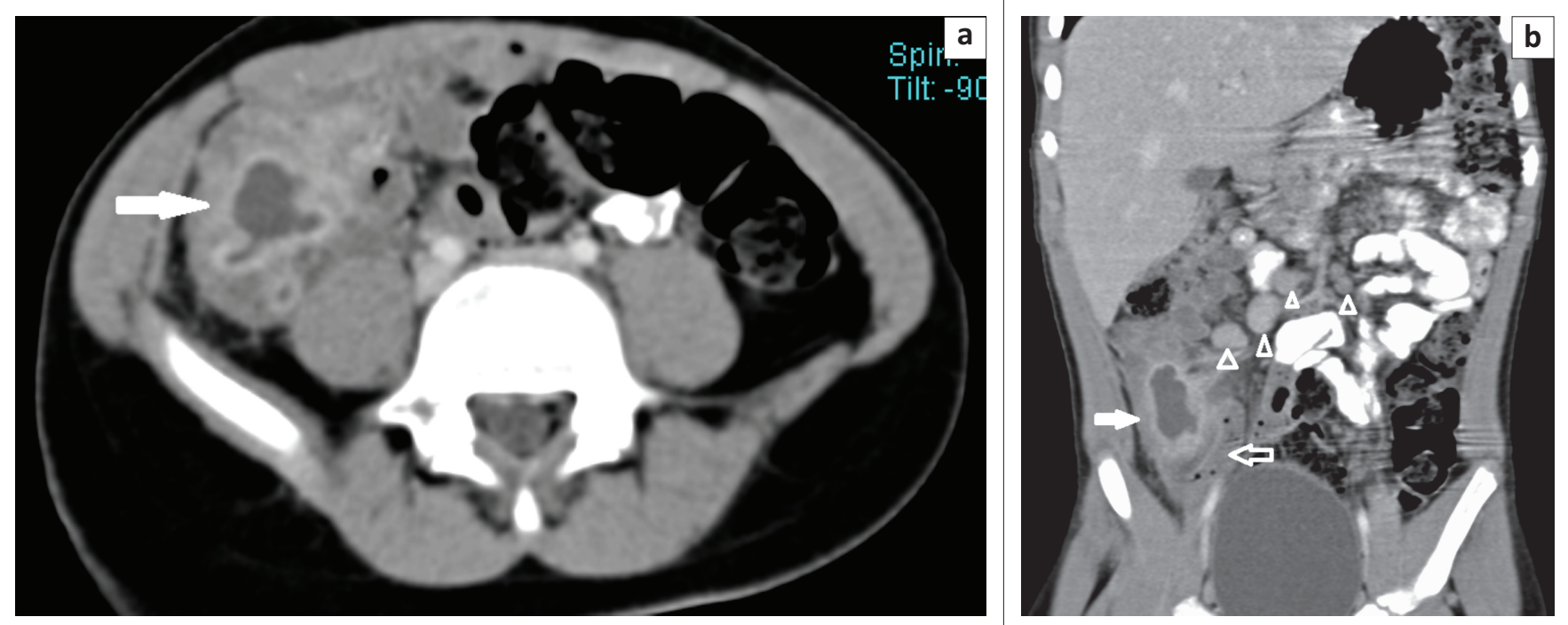

CT, computed tomography.

FIGURE 13: CT images of a known leukaemic patient on treatment. Axial image (a) shows significant mural thickening and mucosa enhancement of the caecum (solid arrow). Coronal image (b) shows significant mural thickening of the caecum and terminal ileum (open arrow) with enlarged lymphadenopathy (open arrowheads).
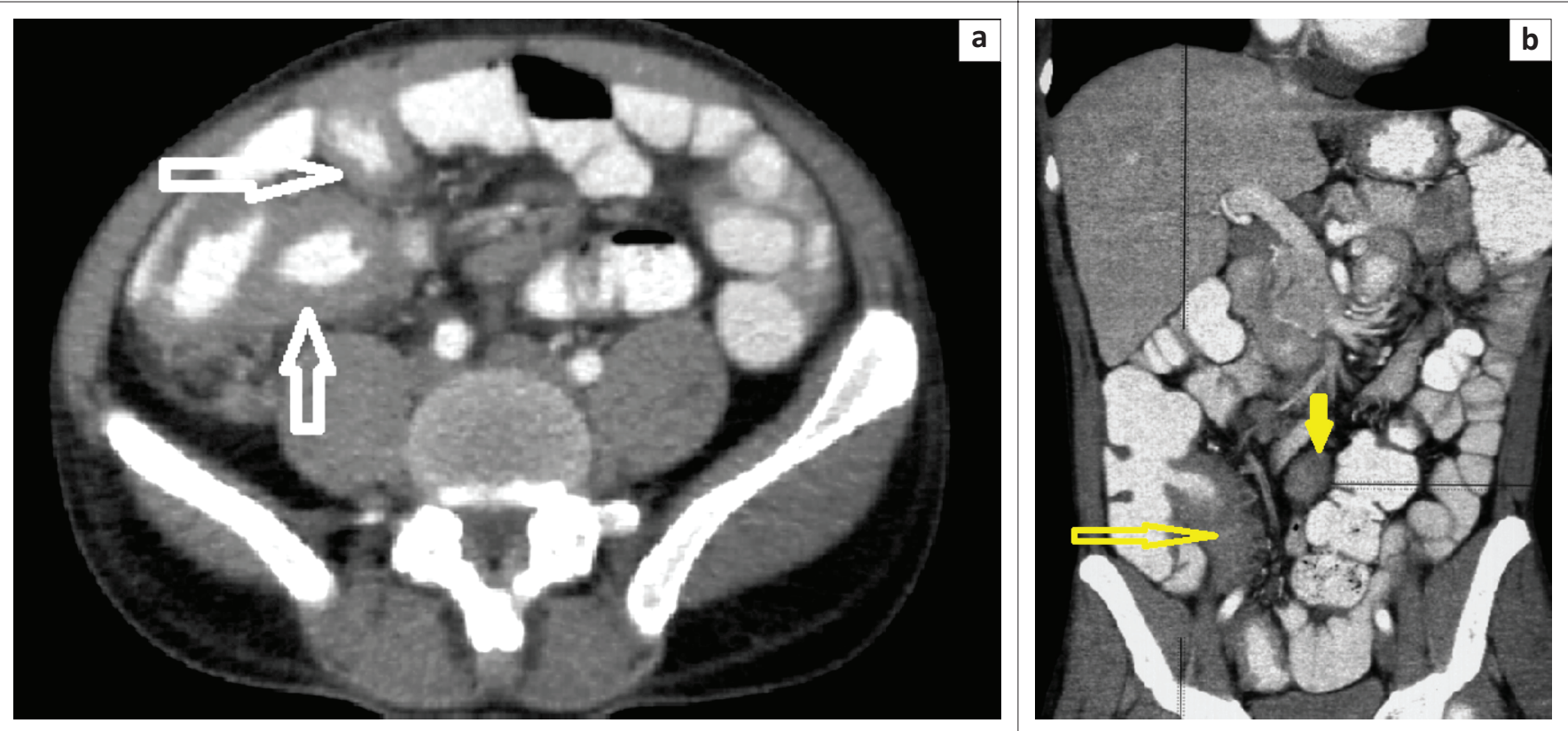

$\mathrm{CT}$, computed tomography.

FIGURE 14: A 23-year-old patient newly diagnosed with lymphoma. Axial MDCT image (a) shows significant mural thickening of the terminal ileum (open white arrows). Coronal image (b) demonstrates enlarged mesenteric lymph nodes (short solid yellow arrow) and significant mural thickening of the terminal ileum (long open yellow arrow). Note that there is no evidence of small bowel obstruction.

\section{Right lower quadrant pain associated with gynaecological diseases}

\section{Pelvic inflammatory disease}

Pelvic inflammatory disease (PID) is seen in sexually active female patients and manifests as lower abdominal pain. The source of infection is usually an ascending lower genital tract infection. PID encompasses endometritis, salpingitis and tubo-ovarian abscesses. Neisseria gonorrhoea and Chlamydia trachomatis are the most common pathogens. ${ }^{23}$

US may demonstrate loss of normal tissue planes and an ill-defined uterus. Thickening of the endometrium may be present, but is nonspecific. Fluid may also be seen in the endometrial cavity. Salpingitis may progress to hydro- or pyosalphinx, and is usually visualised as complex fluid with echogenic debris distending the fallopian tubes. At a later stage, a tubo-ovarian abscess may form. ${ }^{23}$

On CT, a complex hypodense fluid collection with thickened and irregular walls of a tubo-ovarian complex, is seen within the pelvis (Figure 18). ${ }^{23}$

MRI STIR and T2-weighted images may demonstrate a cystic enlarged ovary. On T2-weighted images, signal hyperintensity can be localised within the parametrial tissues. A tubo-ovarian abscess appears with mild T1 hyperintensity 

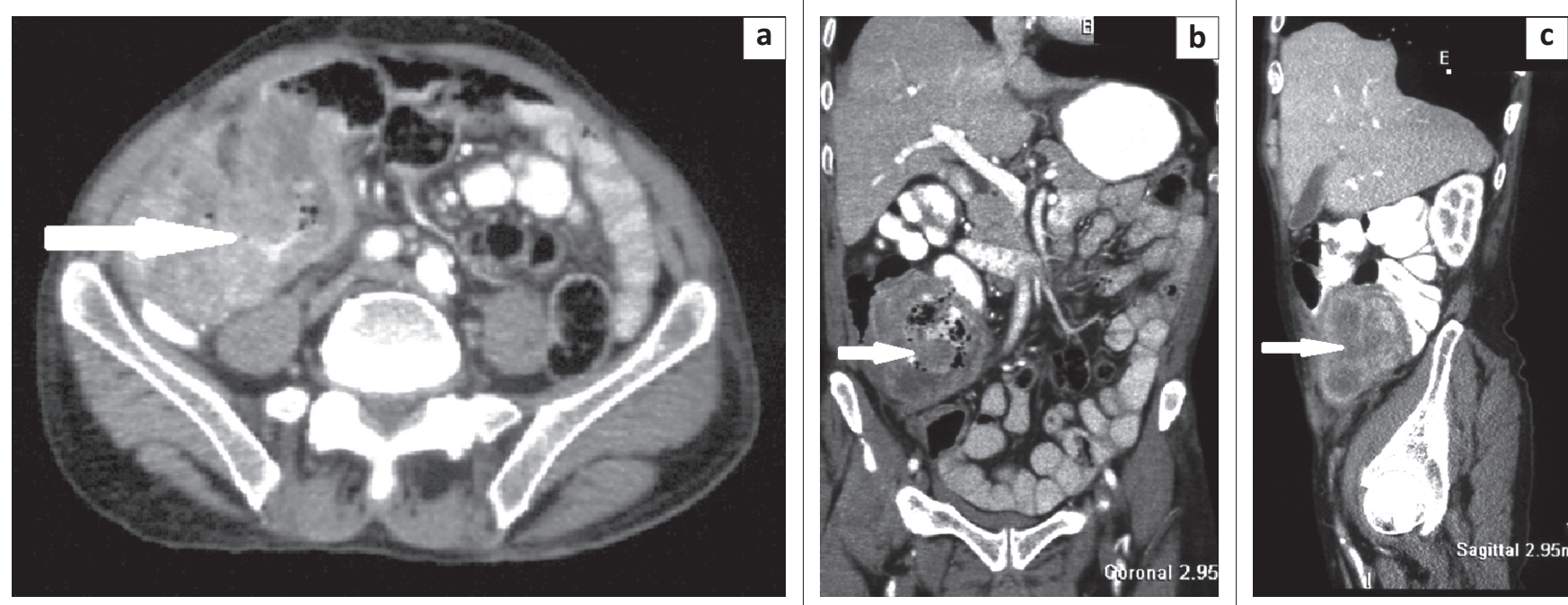

MDCT, multi-detector CT.

FIGURE 15: Axial (a), coronal (b) and sagittal (c) reformatted CT images of a 63-year-old patient with a caecal carcinoma, showing a large concentric heterogeneously enhancing mass causing marked distortion of the caecum (solid arrows).
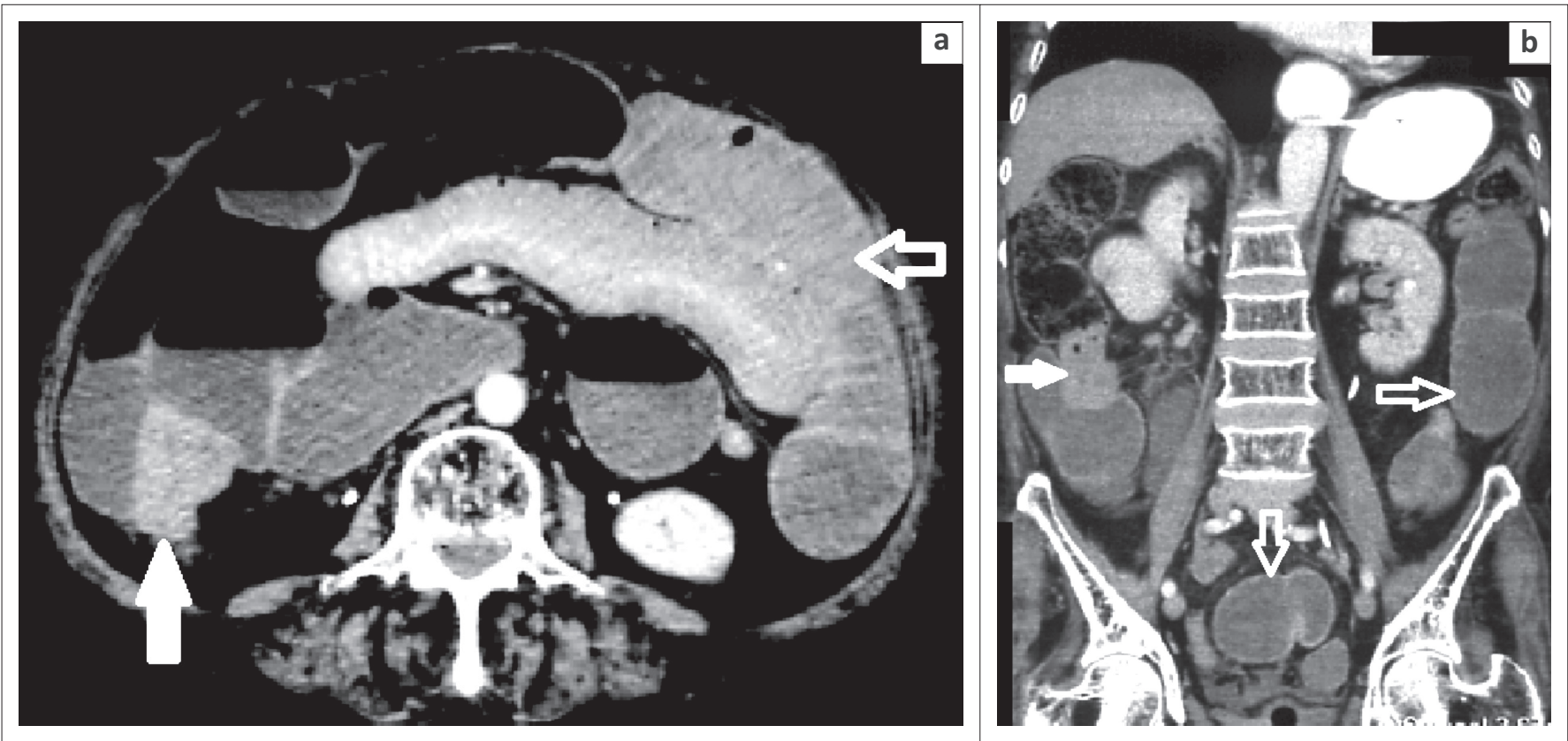

$\mathrm{CT}$, computed tomography.

FIGURE 16: CT images of a 56-year-old patient presenting with features of small bowel obstruction. Axial (a) and coronal (b) images demonstrate a concentric enhancing mass causing stricturing in the proximal ascending colon (solid arrows), with subsequent small bowel obstruction (open arrows).

and high signal intensity on T2-weighted images. Postcontrast MR images demonstrate a thick, enhancing wall of the abscess - with or without an adjacent hydrosalpinx. ${ }^{5,17}$

\section{Endometriosis}

Endometriosisis a chronicgynaecological disordercharacterised by growth of endometrial tissue outside the endometrial cavity primarily in the pelvis, peritoneum and ovaries. ${ }^{24}$ This ectopic mucosa undergoes cyclical hormonal changes and also bleeds, forming haemorrhagic cysts (Figure 19).

Although US can visualise these lesions, CT and MRI are better for evaluating and characterising them. MRI has a greater sensitivity owing to the detection of blood and blood products. These appear as T1 hyperintensities, also known as the light bulb appearance on fat suppression sequence, which results from the intracellular methaemoglobin.

On T2-weighted images, endometriomas appear hypointense. This hypointense signal can also be described as shading that completely occupies the cyst or is seen as a dependent layer. It is thought to be the result of high concentrations of protein and iron from recurrent haemorrhages. ${ }^{17}$ Minimal enhancement is demonstrated on post-contrast scans (Figure 20). ${ }^{24}$

Endometriomas are demonstrated on non-contrast CT scan as areas of hyperattenuation with solid and cystic heterogenous adnexal masses and fluid-fluid levels within the cysts. Cysts often rupture, leading to haemoperitoneum. The sonographic 
appearance of endometrioma demonstrates a uniform, lowlevel echogenicity or a ground glass appearance. The rupture of endometriomas may simulate complex masses, which can make diagnosis challenging. ${ }^{17,23}$

\section{Ectopic pregnancy}

When patients present with features suggestive of an ectopic pregnancy, hormonal ( $\beta$-hCG) levels and pelvic US should

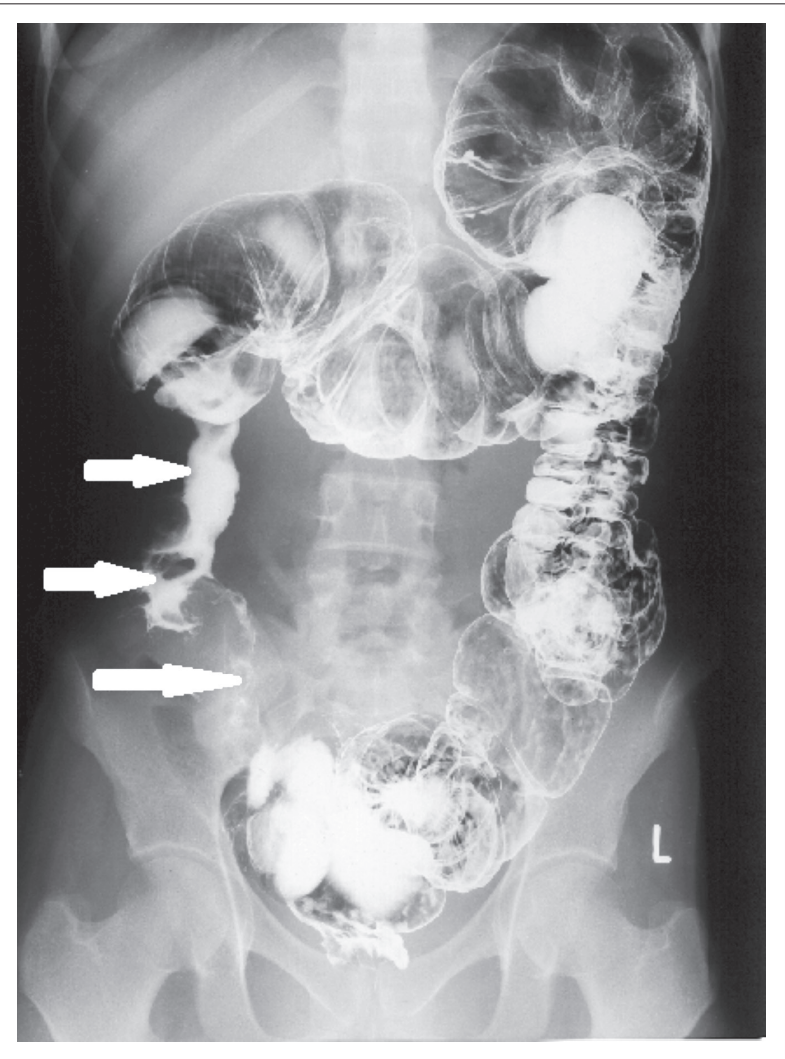

FIGURE 17: An interesting case of a 37-year-old patient presenting with alteration in bowel habit associated with right iliac fossa pain. This supine radiograph in a barium enema series demonstrates marked thickening with luminal narrowing of the caecum, ascending colon and terminal ileum including the ileocaecal valve. A differential diagnosis of Chrohn's disease or lymphoma was given. Interestingly, this was proven to be adenocarcinoma on histological testing. be performed. Transvaginal US is the preferred method of evaluation, although abdominal US can demonstrate ectopic pregnancies when $\beta$-hCG levels exceed $6500 \mathrm{mIU} / \mathrm{ml}^{25}$ Tubal pregnancies are the most common ectopic location. On MRI, a tubal pregnancy is described as a sac-like, cystic tubal structure with a T2 hyperintense thick wall. The cystic sac may demonstrate $\mathrm{T} 1$ hyperintense to intermediate signal intensity, depending on the haemorrhagic component. It is thought that intravenous contrast may help to confidently diagnose an ectopic pregnancy, but contrast is rarely administered in pregnant patients. T2 hyperintensity or T1 hyperintensity may represent free fluid or haemoperitoneum within the abdomen. ${ }^{26}$ Approximately 35\% of ectopic pregnancies may not demonstrate any adnexal abnormalities (Figure 21)..$^{25}$

It is crucial to differentiate normal pregnancy from ectopic pregnancies with the use of US (Table 2).

\section{Right lower quadrant pain associated with miscellaneous causes Intussusception}

Intussusception is not common in adults; it presents as vague abdominal pain, and occurs when a proximal segment of

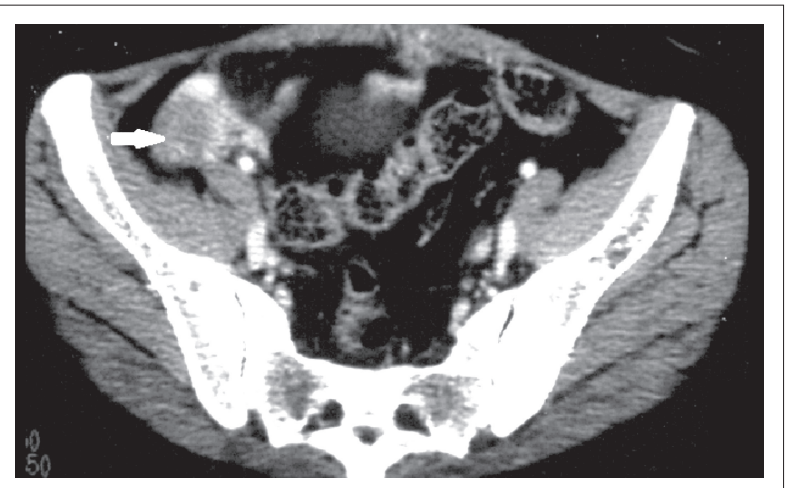

$\mathrm{CT}$, computed tomography.

FIGURE 19: Axial CT image in a young female patient with endometriosis demonstrates a heterogeneously enhancing lesion in the caecum that was found to be an endometriotic deposit at surgery (solid arrow).
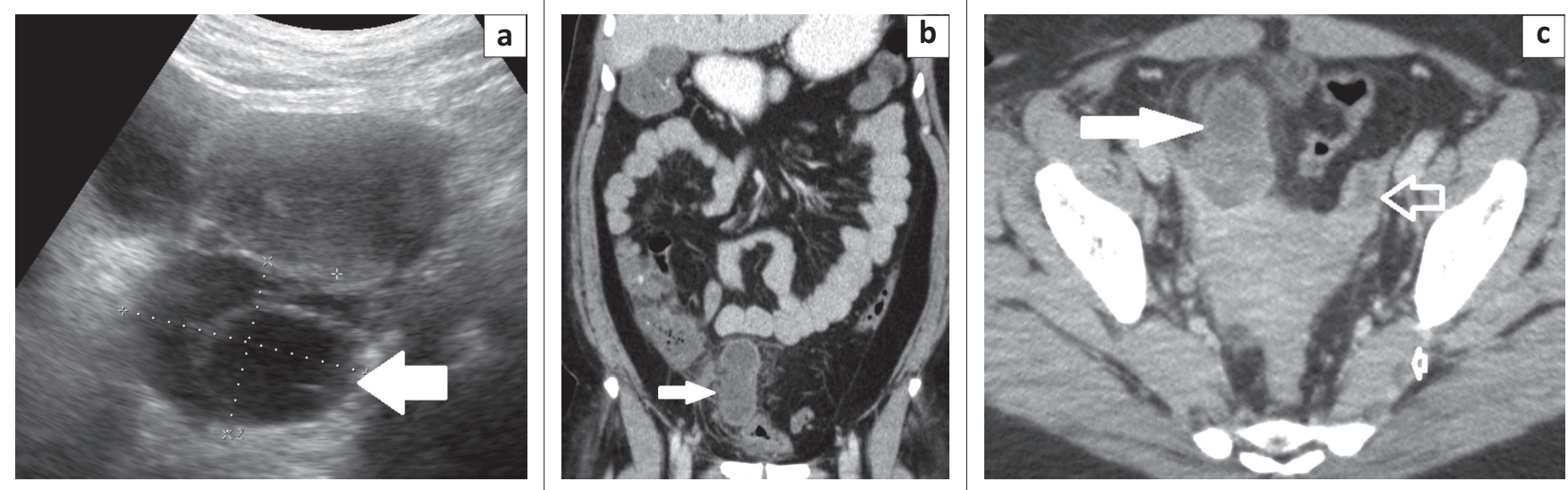

FIGURE 18: Ultrasound and CT images of a 22-year-old woman presenting with right iliac fossa pain. Transabdominal sonographic image (a) demonstrates a complicated hypoechoic cystic mass with low-level internal septations in the right adnexa (solid arrow). Coronal (b) and axial (c) contrast-enhanced CT confirmed the tubular-appearing, rim-enhancing hypodense fluid collection in keeping with a tubo-ovarian abscess (solid arrows). Axial CT (c) shows a smaller lesion on the left (small open arrow). 

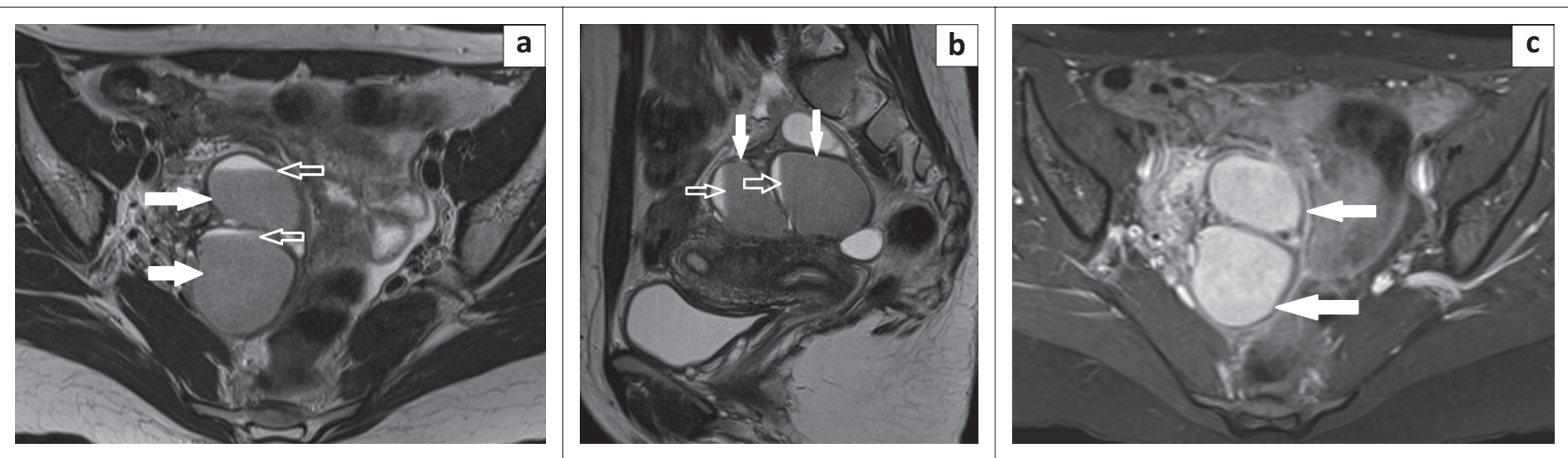

FIGURE 20: Magnetic resonance images of a young female patient with endometriosis. Axial (a) and sagittal (b) T2-weighted images without fat saturation show two endometriotic cysts within the pelvis (solid arrows), with dependent fluid levels (open arrows) of low signal intensity blood products. Shading is visualised in both the cysts. Axial post-contrast T1 image with fat saturation (c) shows minimal enhancement, with fluid levels still noted (solid arrows).
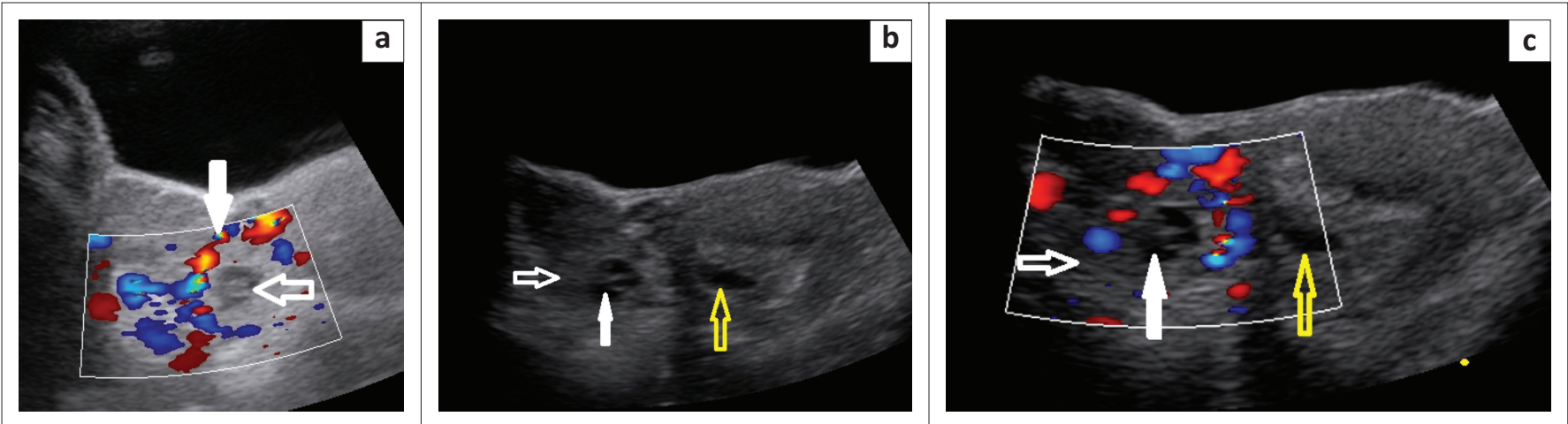

FIGURE 21: Transabdominal ultrasound images ( $a, b, c)$ of a young pregnant female patient with right iliac fossa pain. Longitudinal scan (a) demonstrates a thick-walled cystic lesion in the right adnexa with a yolk sac and fetus within (open arrow), demonstrating a ring of fire appearance, with colour uptake (solid arrow). Tranverse images (b, c) show the tubal ring sign - a hyperechoic rim surrounding the extra-uterine sac (open arrow), the ectopic pregnancy (solid arrow) and an empty uterine cavity with a pseudo-gestational sac appearance (yellow arrow).

TABLE 2: Comparison of sonographic features in normal intrauterine and ectopic pregnancies.

\section{Intrauterine pregnancy \\ Intradecidual sign -4.5 weeks, eccentrically located collection of fluid within endometrium surrounded by hyperechoic ring}

Double decidual sac sign -5 weeks, 2 concentric hyperechoic rings surrounding anechoic gestational sac

Secondary yolk sac -5.5 weeks

Embryonic cardiac activity -5 to 6 weeks

bowel (intussusceptum) telescopes into an adjacent distal segment (intussuscipiens) (Figure 22).

In adults, there is often an underlying lead point such as benign or malignant neoplasms (e.g. lipoma, polyps, lymphoma, carcinoma, metastases and leiomyomas). In contrast with children, operative treatment is usually necessary in adults. ${ }^{1,16,27}$ Gayer et al. report an increased incidence of intussusception in patients with AIDS; compare the association of AIDS with numerous infectious and neoplastic conditions (infectious enteritis, Kaposi's sarcoma, non-Hodgkin's lymphoma). Intussusception should be considered in AIDS patients with prolonged abdominal pain. ${ }^{27}$ Although diagnosis can be made using other imaging modalities (including barium enema, US and gastrointestinal
Ectopic pregnancy

Absence of intrauterine gestational sac/extrauterine sac with yolk sac or embryo

Tubal ring sign - hyperechoic ring surrounding an extrauterine gestational sac

Ring of fire sign - peripheral vascularity of the hyperechoic ring, non-specific (also seen in corpus luteum cyst)

Intrauterine findings - normal endometrium, pseudo-gestational sac, trilaminar endometrium, thin-walled decidual cyst

Extrauterine findings - pelvic free fluid, haematosalpinx, haemoperitoneum series), CT is considered the modality of choice. Not only can the diagnosis be made accurately, but the cause and complications - such as bowel obstruction - can be assessed (Figure 23). The three typical characteristics are the reniform appearance, sausage appearance and target-shaped bowelwithin-bowel appearance..$^{1,16,27}$

\section{Caecal volvulus}

Caecal volvulus is seen in patients with an abnormally mobile caecum; this allows twisting along the long axis, leading to bowel obstruction. Three types of caecal volvulus have been described:

- type 1: the caecum twists in the axial plane, rotating along its long axis 
- type 2: the distended caecum twists and inverts

- type 3: caecal bascule - the distended caecum folds anteriorly, without torsion.

The diagnosis of caecal volvulus and its complications (ischaemia and obstruction) can be readily made using MDCT. A distended caecum and swirl of mesenteric vessels is demonstrated in types 1 and 2 caecal volvulus. Concentric wall thickening, mesenteric fat stranding, and pneumatosis intestinalis are all signs related to complications. ${ }^{1}$

In addition to the causes of right lower quadrant pain enumerated and discussed above, six other causes are listed, together with their respective imaging findings, in Table 3.

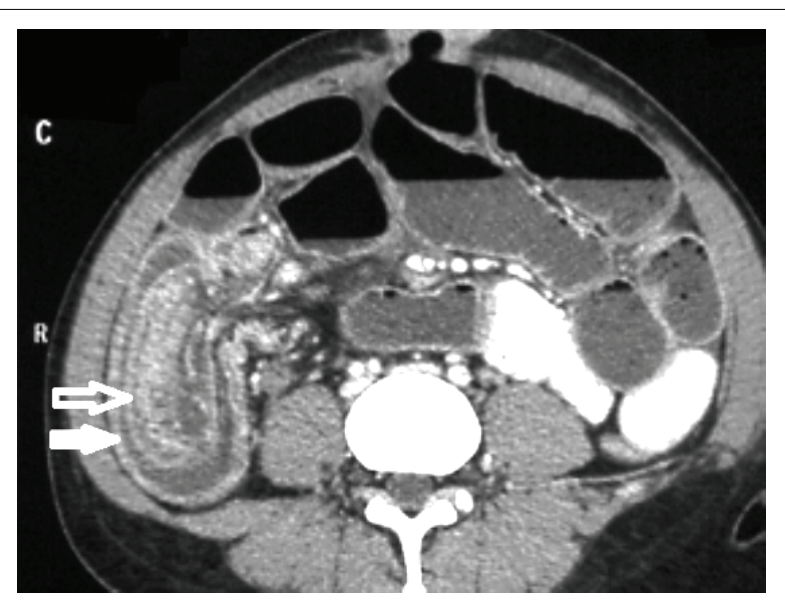

FIGURE 22: Axial CT image of a young patient showing an ileocaecal intussusception with an intussusceptum (open arrow) and an intussuscipens (solid arrow).

\section{Diagnostic algorithm}

There is a wide spectrum of conditions affecting the right lower quadrant, some with disease-specific investigations and imaging modalities. Therefore it is vital that a structured guideline be used. The Department of Health in Western Australia has devised several diagnostic imaging pathways as a guide for their practitioners. These pathways are reviewed and updated periodically. The imaging pathway for right iliac fossa pain is particularly pertinent for use in the South African medical setting as it is practical and takes into consideration local availability and imaging constraints (Figure 24).

\section{Conclusion}

Right lower quadrant pain is a common clinical situation. When considering imaging, age and sex of the patient are essential factors, as the differential diagnoses may differ. $^{2}$ ACR criteria still rate US and CT as the primary imaging modalities for evaluating acute abdominal and pelvic conditions such as appendicitis, diverticulitis, PID and ectopic pregnancy. ${ }^{5}$ US is clearly preferred in young and pregnant patients, whilst CT is considered first-line imaging for the elderly and those with peritonism. ${ }^{2} \mathrm{MRI}$ is not the modality of choice in all patients, but is a method with high accuracy and may be beneficial in a subset of patients for whom CT is not warranted. ${ }^{5}$ All these imaging modalities are of value under certain circumstances, and must not oppose each other but rather have complementary functions, which will allow precise diagnosis and prompt management of patients presenting with right lower quadrant pain. ${ }^{1,2}$
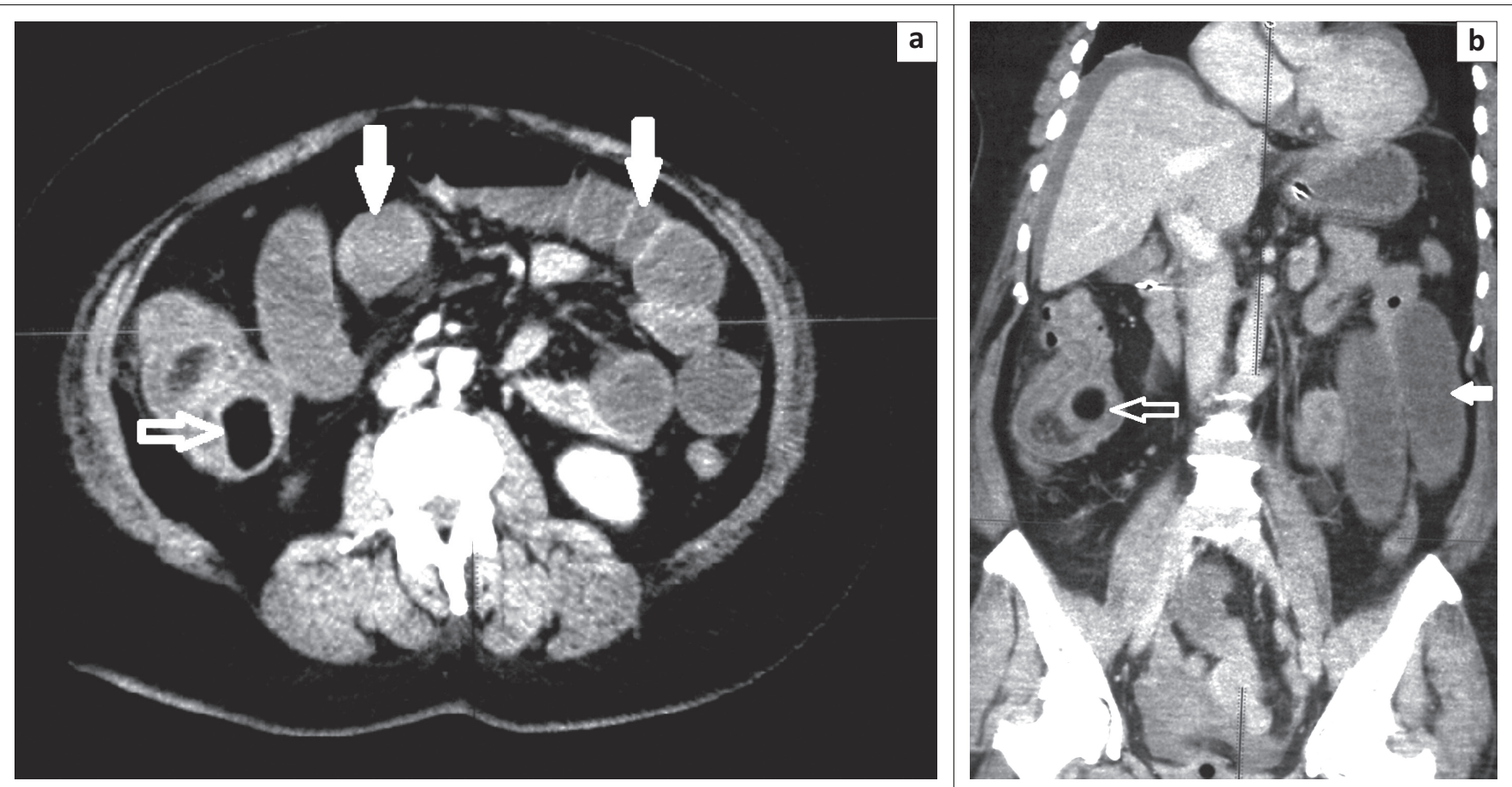

$\mathrm{CT}$, computed tomography

FIGURE 23: A 19-year-old patient presented with vomiting. Axial (a) and coronal (b) CT images show an ileocolic intussusception with a lipoma as a lead point (open arrows); this caused subsequent small bowel obstruction (solid arrows). 
TABLE 3: Causes of right lower quadrant pain and their associated imaging findings - not listed or discussed in the text.

\section{Cause}

Ischaemic colitis: Occlusive/thrombo-embolic or nonocclusive, right colonic ischaemia - increased mortality when compared with the left side.

Patients usually present with pain as opposed to rectal bleeding as occurs in the left colon.

Ovarian torsion: Ovary and its surrounding tissues twist on its vascular pedicle. Can occur in normal ovaries or in relation to a benign adnexal mass.

\section{Cholecystitis: Mostly owing to gallstones.}

Renal colic: Urolithiasis is increasingly prevalent with high recurrence rates. CT is now utilised for diagnosis, treatment planning and post-treatment follow-up.

Mesenteric adenitis: Primary or secondary.

Omental infarction: Caused by vascular compromise from torsion or venous thrombosis.

$\mathrm{CT}$, computed tomography; MDCT, multi-detector CT.

\section{Imaging findings}

- CT findings: Early hyperenhancement of the mucosa, then bowel wall thickening owing to submucosal oedema.

- Persistent ischaemia - reduced or absent enhancement with bowel dilatation.

- Late findings - intramural gas (pneumatosis coli) and gas in the portal or mesenteric vessels - ensuing infarction.

- Pathognomonic sign of transmural necrosis is perforation with pneumoperitoneum or

pneumoretroperitoneum. $28,29,30$

- Ultrasound features rely on the chronicity of the torsion.

- Engorgement of the ovary with central hyperechogenicity and peripheral follicles; occasionally, a cyst may be found.

- If torsion progresses, haemorrhagic infarction occurs with hypoechoic areas as well as free fluid.

- Owing to the dual blood supply to the ovary, high-grade torsion is required for inflow occlusion to occur.

- Colour Doppler equivocal: Longitudinal scanning along the vascular pedicle may demonstrate swirling of the

vasculature, called the pathognomonic whirlpool sign.

- If clinically suspected, on $\mathrm{CT}$, an enlarged ovary $>5 \mathrm{~cm}$ with or without a cystic adnexal mass may suggest torsion. ${ }^{31,32}$

- Ultrasound is more sensitive for detection of calculi.

- Ultrasound features include gallbladder wall thickening $(3 \mathrm{~mm})$, wall oedema, gallbladder distention $(4 \mathrm{~cm})$, positive sonographic Murphy sign, and pericholecystic fluid.

- CT with intravenous contrast: Acute cholecystitis depicted pericholecystic fat stranding, hypo- or

hyperattenuating gallstones and hyperattenuation of the gallbladder fossa.

- CT is useful in assessing complicated cholecystitis such as emphysematous, gangrenous cholecystitis, haemorrhage, gallstone ileus and perforation..$^{33}$

- Unenhanced CT has become the gold standard in many centres for detection of renal calculi, with a limited role for ultrasound.

- MDCT provides valuable information regarding stone burden (size), composition (Hounsfield unit) and fragility (heterogeneity) - which affects management.

- Recent introduction of dual-energy MDCT is promising in improving characterisation of renal stone composition.

- Further studies using virtual non-enhanced dual-energy CT revealed no greater benefit, as the detection of small stones was limited. ${ }^{34,35}$

- Primary: CT - right-sided clustered (more than three) mesenteric lymph nodes without an identifiable cause, and measuring $>5 \mathrm{~mm}$

- Secondary: Present as a result of local inflammatory conditions 36,37

- CT features: Solitary, well-defined triangular or oval fatty mass. May have a whorled appearance, and is usually found between the anterior abdominal wall and the transverse or ascending colon ${ }^{38,39}$

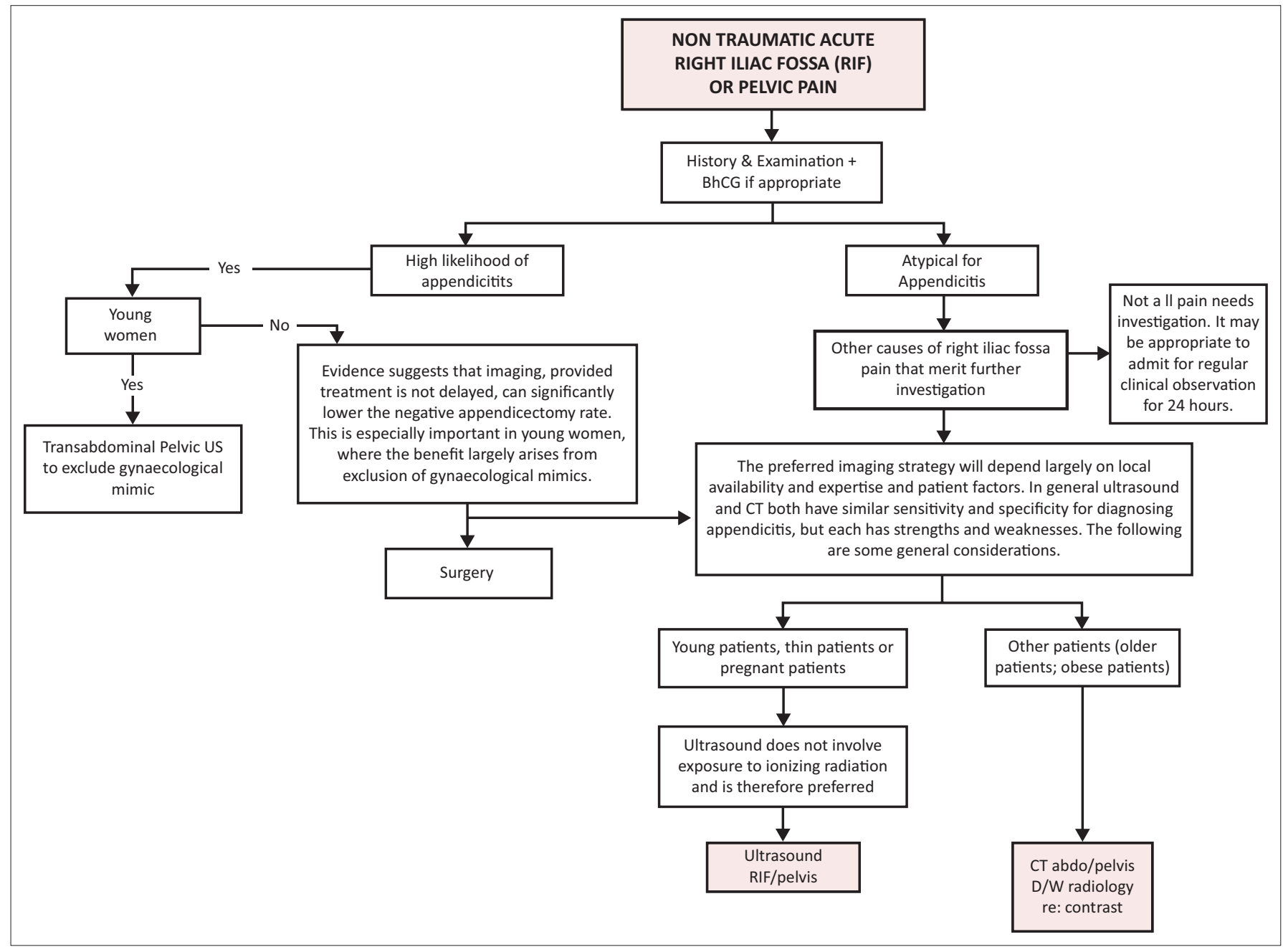

Source: Department of Health Western Australia ${ }^{40}$

FIGURE 24: Diagnostic imaging pathway of right iliac fossa pain. 


\section{Acknowledgements}

We thank Dr J. Maharajh and Dr A. Mitha for their help in compiling the images.

\section{Competing interests}

The authors declare that they have no financial or personal relationship(s) that may have inappropriately influenced them in writing this article.

\section{Authors' contributions}

Both authors have contributed in various degrees to the article produced. P.N. (University of KwaZulu-Natal) was responsible for the study conception and design, acquisition and analysis of data and drafting of manuscript. B.S. (University of KwaZulu-Natal) was responsible for the analysis and interpretation of data and the critical revision of manuscript.

\section{References}

1. Purysko AS, Remer EM, Leão Filho HM, Bittencourt LK, Lima RV, Racy DJ. Beyond appendicitis: Common and uncommon gastrointestinal causes of right lowe quadrant abdominal pain at multidetector CT. Radiographics. 2011;31(4):927947. http://dx.doi.org/10.1148/rg.314105065

2. Millet I, Alili C, Pages E, et al. Infection of the right iliac fossa. Diagn Interv Imaging. 2012;93:441-452. http://dx.doi.org/10.1016/j.diii.2012.04.026

3. Patel SF, Reede DL, Katz DS, et al. Imaging the pregnant patient for non-obstetric conditions: Algorithms and radiation dose considerations. Radiographics. conditions: Algorithms and radiation dose consideration

4. Spalluto LB, Woodfield CA, DeBenedectis CM, et al. MR imaging evaluation of abdominal pain during pregnancy: Appendicitis and other nonobstetric causes. Radiographics. 2012;32:317-334. http://dx.doi.org/10.1148/rg.322115057

5. Heverhagen JT, Klose KJ. MR imaging for acute lower abdominal and pelvic pain. Radiographics. 2009;29:1782-1796. http://dx.doi.org/10.1148/rg.296095518

6. Kin HC, Yang DM, Fin W, et al. Added diagnostic value of multiplanar reformation of multidetector CT data in patients with suspected appendicitis. Radiographics. 2008;28:393-406.

7. Simpson J, Scholefield JH. Acute appendicitis. Surgery. 2008;26(3):108-112 http://dx.doi.org/10.1016/j.mpsur.2008.01.003

8. Rao PM, Wittenberg J, McDowell RK, et al. Appendicitis: Use of the arrowhead sign for diagnosis at CT. Radiology. 1997;202:363-366. http://dx.doi.org/10.1148/ radiology.202.2.9015058

9. Rao PM, Rhea JT, Novelline RA. Distal appendicitis: CT appearance and diagnosis. Radiology. 1997;204:709-712. http://dx.doi.org/10.1148/radiology.204.3.9280247

10. Shin LK, Halpern D, Weston SR, et al. Prospective CT diagnosis of stump appendicitis. AJR. 2005;184:S62-S64. http://dx.doi.org/10.2214/ajr.184.3_ supplement.01840s62

11. Sharma M, Agrawal A. Pictorial essay: CT scan of appendicitis and its mimics causing right lower quadrant pain. Indian J Radiol Imaging. 2008;18:80-89. http:// dx.doi.org/10.4103/0971-3026.37051

12. Ganguli S, Raptopoulos V, Komlos F, et al. Right lower quadrant pain: Value of the nonvisualised appendix in patients at multidetector CT. Radiology. 2006;241:175180. http://dx.doi.org/10.1148/radiol.2411050191

13. Nikolaidis $P$, Hwang $C M$, Miller FH, et al. The nonvisualised appendix: incidence of acute appendicitis when secondary inflammatory changes are absent. AJR. 2004;183:889-892.

14. Tkacz FN, Anderson SA, Soto F. MR imaging in gastrointestinal emergencies. Radiographics. 2009;29:1767-1780. http://dx.doi.org/10.1148/rg.296095509

15. Pedrosa I, Levine D, Eyvazzadeh $A D$, et al. MR imaging evaluation of acute appendicitis in pregnancy. Radiology. 2006;238:891-899. http://dx.doi. org/10.1148/radiol.2383050146
16. Silva A, Beaty SD, Hara AK, et al. Spectrum of normal and abnormal CT appearances of the ileocecal valve and cecum with surgical correlation. Radiographics. 2007;27:1039-1054. http://dx.doi.org/10.1148/rg.274065164

17. Singh A, Danrad R, Hahn PF, et al. MR imaging of the acute abdomen and pelvis: Acute appendicitis and beyond. Radiographics. 2007;27:1419-1431. http:// dx.doi.org/10.1148/rg.275065021

18. Sempere GA, Sanjuan VM, Chulia EM, et al. MR evaluation of inflammatory activity in Crohn's disease. AJR. 2005;184(6):1829-1835. http://dx.doi.org/10.2214/ ajr.184.6.01841829

19. Burrill J, Williams CF, Bain G. Tuberculosis: A radiologic review. Radiographics. 2007;27:1255-1273. http://dx.doi.org/10.1148/rg.275065176

20. Pulimood AB, Amarpurkar DN, Ghoshal U, et al. Differentiation of Crohn's disease from intestinal tuberculosis in India in 2010. World J Gastroenterol. 2011;17(4):433-443. http://dx.doi.org/10.3748/wjg.v17.i4.433

21. Bunni J, Corrigan A, Jacob K, et al. Epiploic appendagitis: A case report highlighting correlation between clinical features, computed tomography images and laparoscopic findings. Int J Surg. 2010;8:401-403. http://dx.doi.org/10.1016/j. ijsu.2010.04.010

22. Taylor CR, Pfeifer KE, Wang SY. Imaging in adenocarcinoma of the colon [homepage on the Internet]. No date [cited 2013 Aug. 7]. Available from http://emedicine. medscape.com/article/367061-overview

23. Potter AW, Chandrasekhar CA. Ultrasound and CT evaluation of acute pelvic pain of gynaecological origin in nonpregnant premenopausal patients. Radiographics. 2008;28:1645-1659. http://dx.doi.org/10.1148/rg.286085504

24. Chamie LP, Blasbalg R, Pereira RMA, et al. Findings of pelvic endometriosis at transvaginal US, MR imaging and laparoscopy. Radiographics. 2011;31:77-100. http://dx.doi.org/10.1148/rg.314105193

25. Lin PE, Bhatt S, Dogra VS. Diagnostic clues to ectopic pregnancy. Radiographics. 2008;28:1661-1671. http://dx.doi.org/10.1148/rg.286085506

26. Parker III RA, Yano M, Tai AW, et al. MR imaging findings of ectopic pregnancy: A pictorial review. Radiographics. 2012;32:1445-1460. http://dx.doi.org/10.1148/ rg.325115153

27. Gayer G, Zissin R, Apter S, et al. Adult intussusception - a CT diagnosis. Br J Radiol. 2002;75(890):185-190. http://dx.doi.org/10.1259/bjr.75.890.750185

28. Angelelli G, Scardapane A, Memeo M, et al. Acute bowel ischemia: CT findings. Eur J Radiol. 2004;50(1):37-47. http://dx.doi.org/10.1016/j.ejrad.2003.11.013

29. Brandt LJ, Feuerstadt P, Blaszka MC. Anatomic patterns, patient characteristics, and clinical outcomes in ischemic colitis: A study of 313 cases supported by histology. Am J Gastroenterol. 2010;105(10):2245-2252. http://dx.doi. org/10.1038/ajg.2010.217

30. Romano S, Romano L, Grassi R. Mulidetector row computed tomography findings from ischemia to infarction of the large bowel. Eur J Radiol. 2007;61(3):433-441. from ischemia to infarction of the large bowel.
http://dx.doi.org/10.1016/j.ejrad.2006.11.002

31. Stark JE, Siegel MJ. Ovarian torsion in prepubertal and pubertal girls: Sonographic findings. AJR. 1994;63:1479-1482. http://dx.doi.org/10.2214/ ajr.163.6.7992751

32. Vijayaraghavan SB. Sonographic whirlpool sign in ovarian torsion. J Ultrasound Med. 2004;23:1643-1649.

33. O'Conner OJ, Maher MM. Imaging of cholecystitis. AJR. 2011;196(4):W367W374. http://dx.doi.org/10.2214/ajr.10.4340

34. Kambadakone AR, Eisner BH, Catalano A, et al. New and evolving concepts in the imaging and management of urolithiasis: Urologists' perspective. Radiographics. 2010;30:603-623. http://dx.doi.org/10.1148/rg.303095146

35. Takahashi N, Vrtiska TJ, Kawashima A, et al. Detectability of urinary stones on virtual non-enhanced images generated at pyelographic-phase dualenergy CT. Radiology. 2010;256(1):184-190. http://dx.doi.org/10.1148/ radiol.10091411

36. Macari M, Hines J, Balthazar E, et al. Mesenteric adenitis: CT diagnosis of primary versus secondary causes, incidence, and clinical significance in pediatric and adult patients. AJR. 2002;178:853-858. http://dx.doi.org/10.2214/ ajr.178.4.1780853

37. Lucey BC, Stuhlfaut JW, Soto FA. Mesenteric lymph nodes seen at imaging: Causes and significance. Radiographics. 2005;25:351-365. http://dx.doi.org/10.1148/ rg. 252045108

38. Puylaert JBCM. Right-sided segmental infarction of the omentum: Clinical, US, and CT findings. Radiology. 1992;185:169-172.

39. Pereira JM, Sirlin CB, Pinto PS, et al. Disproportionate fat stranding: A helpful CT sign in patients with acute abdominal pain. Radiographics. 2004;24:703-715. sign in patients with acute abdominal
http://dx.doi.org/10.1148/rg.243035084

40. Department of Health Western Australia. Diagnostic Imaging Pathways [homepage on the Internet]. Available from http://imagingpathways.health. wa.gov.au 